Discussion

Papers

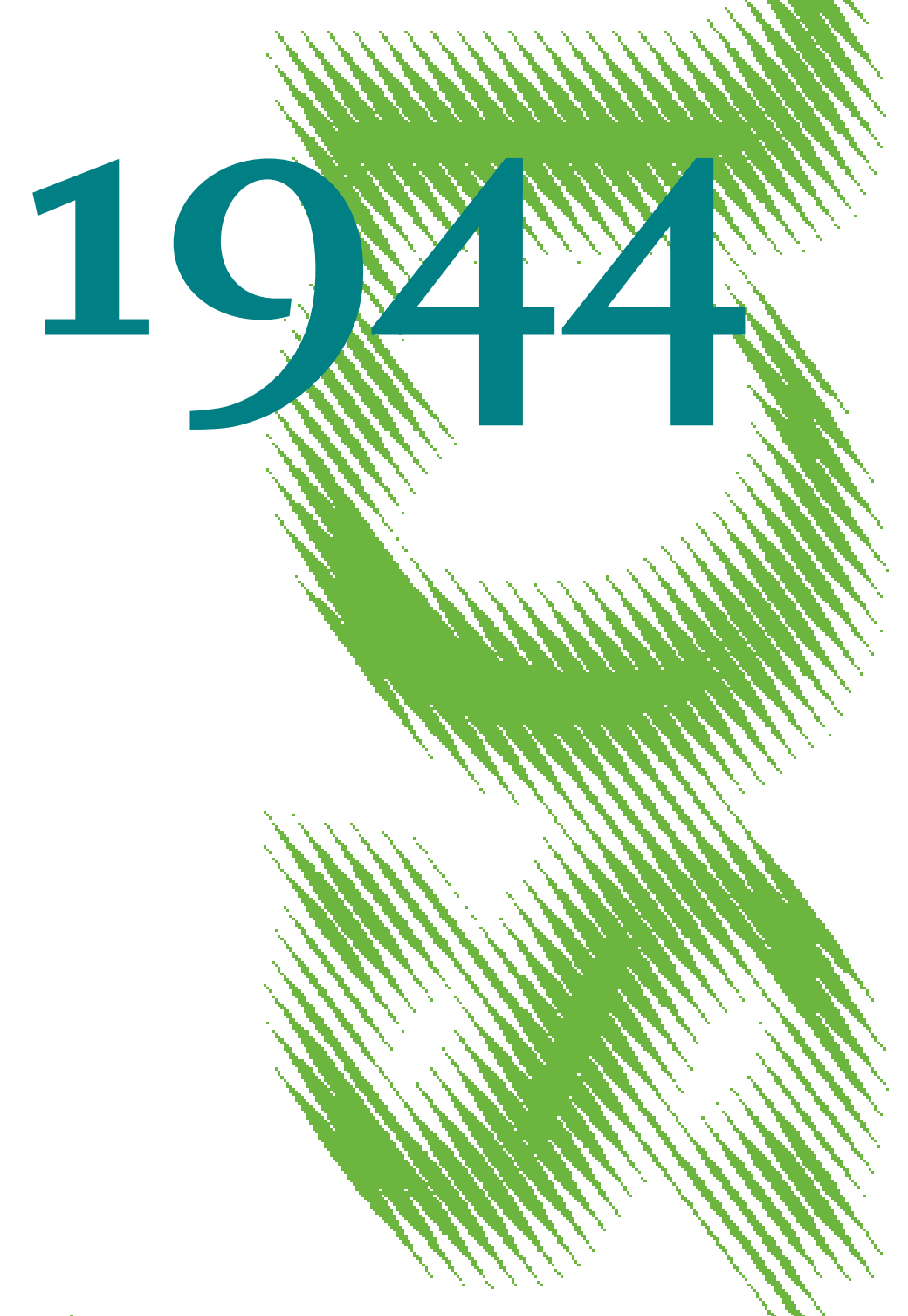

\title{
Temporary VAT Reduction during the Lockdown
}


Opinions expressed in this paper are those of the author(s) and do not necessarily reflect views of the institute.

IMPRESSUM

(C) DIW Berlin, 2021

DIW Berlin

German Institute for Economic Research

Mohrenstr. 58

10117 Berlin

Tel. +49 (30) $89789-0$

Fax +49 (30) $89789-200$

http://www.diw.de

ISSN electronic edition 1619-4535

Papers can be downloaded free of charge from the DIW Berlin website:

http://www.diw.de/discussionpapers

Discussion Papers of DIW Berlin are indexed in RePEc and SSRN:

http://ideas.repec.org/s/diw/diwwpp.html

http://www.ssrn.com/link/DIW-Berlin-German-Inst-Econ-Res.html 


\title{
Temporary VAT Reduction during the Lockdown
}

\author{
Marius Clemens, Werner Röger** \\ First version: May 2021 \\ This (updated) version: May 2022
}

\begin{abstract}
This paper evaluates the temporary VAT reduction introduced by the German government over the 3Q2020:4Q2020 as a controversial part of the COVID-19 stimulus package. Critics argue that VAT reductions are ineffective because of limited pass-through to consumer prices and during lockdown. Advocates emphasize positive effects on durable goods and stress that a VAT reduction can partly substitute for a limited monetary policy response under the zero lower bound (ZLB). Thus, the VAT policy experiment of a sizable two-quarter VAT reduction allows studying the effects and transmissions channels of VAT measures.

We extend a dynamic stochastic equilibrium (DSGE) model to address a durable goods channel and a limited VAT pass-through and distinguish between sectors directly and indirectly affected by the lockdown. We trace lockdown and fiscal shocks and analyze the impact of the VAT reduction in conjunction with the lockdowns in 2020-2021 in Germany.

We use nonlinear solution techniques to solve the model in the presence of a ZLB, forced savings and a partial lockdown constraint. Although the lockdown restriction reduces the effectiveness of a temporary VAT reduction, we find a short-term multiplier of 1.8 . However, the cumulative multiplier reduces to below 1 over the medium term due to a shift in durable goods consumption toward 2020. Thus, the temporary VAT reduction is an effective instrument for short-term stabilization during the partial lockdown, but fiscal costs appear in the medium term.
\end{abstract}

JEL:E62, E65, H12

Keywords: Value added tax, fiscal policy, COVID-19, lockdown, multiplier, Germany

*DIW Berlin, BERA. Email address: mclemens@diw.de.

**DIW Berlin, EIIW, VIVES KU Leuven. Email address: w.roeger@web.de. 


\section{Introduction}

The German government decided to stimulate the economy via a temporary VAT rate reduction due to the COVID19 pandemics. From 1st July 2020 to the end of the year, the regular VAT rate was reduced from 19 to $16 \%$. The VAT rate on necessities, such as food and books, was reduced from 7 to $5 \%{ }^{1}$ The VAT reduction was part of a large stimulus package of 160 billion euros that the German government launched to stabilize and stimulate the economy after the first lockdown.

The German VAT measure was accompanied by considerable criticism. "Not targeted enough", "ineffective in the presence of lockdown measures" and "too costly because of limited pass-through to consumer prices" were the main arguments against this instrument. Furthermore, the second lockdown, which started in the fourth quarter, was believed to counteract the VAT cut.

Arguments can be made in favor of VAT reductions: lockdown measures have negative demand spillovers to other consumer-goods-providing sectors that are not directly affected by the lockdown (see Guerrieri et al. (2020)). Thus, a broad instrument such as a VAT reduction can also stabilize demand in sectors not directly affected by the lockdown. Furthermore, VAT reductions could especially be powerful if the central bank operates at the zero lower bound (ZLB) (see Correia et al. (2013)) and, in particular, if the lockdown measures are disinflationary. In this case, durable goods consumption will generally be more negatively affected because of the implied temporary increase in the real interest rate. Thus, VAT reductions could stabilize the demand for consumer durable goods.

In this paper, we make use of the German VAT experiment to analyze the macroeconomic effects of a temporary VAT change during the (partial) lockdown. We set up a dynamic stochastic general equilibrium (DSGE) model for Germany under a (partial) lockdown and with monetary policy operating at the ZLB. We add the following features that make it especially suitable for dealing with the issues raised above. First, we distinguish between durable and non-durable goods in the model and address whether demand spillovers are stronger on durable goods in a lockdown and the possibly larger impact of temporary VAT reductions on durable goods. Ignoring durable goods could lead to an underestimation of the VAT impact. Second, we model the demand for durable goods both for financially unconstrained and for liquidity-constrained (LC) households. Third, we explicitly model a partial lockdown and distinguish between sectors affected and not affected by the lockdown. This allows us to adequately trace the macroeconomic effects of measures that only affect specific sectors of the economy but have spillover effects on the rest of the economy. In this way, we are not inflating the effects of VAT measures because we control for the fact that a fraction of the retail sector is closed. Fourth, we consider imperfect pass-through of VAT measures to consumer prices by differentiating price adjustment costs that are due to VAT changes from other sources. We calibrate the model for Germany and trace how lockdown shocks have affected the main German macroeconomic aggregates over the period 2Q2020:2Q2021. We are especially interested in studying how our identified policy measures improve the fit of the model for GDP and its components and for the consumer price index over that period. In our simulation exercise, we consider that the VAT reduction in the third and fourth

\footnotetext{
${ }^{1}$ Furthermore, in June 2020, a reduced VAT rate was applied to restaurant supplies (supplies of prepared food in place) until June 2021. During the second lockdown, this temporary measure was extended until the end of 2022.
} 
quarters and the lockdown shock in the fourth quarter are unanticipated.

Our study contributes to the empirical literature on temporary VAT changes, which have rarely been empirically observed. The most prominent international example in the last years was a temporary VAT cut from $17.5 \%$ to $15 \%$ in the United Kingdom from December 2008 until the end of 2009. For the U.K.'s VAT reduction, Barrell and Weale (2009) find a 1\% increase in consumption and a half-percent GDP increase. Once the VAT switches back to its original level, both consumption and GDP are depressed. Furthermore, Crossley et al. (2009) find that the income effect is small, while the intertemporal substitution effect is large. According to their estimates, households' willingness to move spending from one year into an earlier (or later) year suggests that a $1 \%$ drop in the price today will translate into a $1 \%$ increase in spending. Because roughly only half of goods purchased are subject to VAT, the $2.5 \%$ rate cut is like a $1.25 \%$ cut in contemporaneous prices. Crossley et al. (2014) find a significant drop in sales after the VAT cut ended. Thus, an indirect tax cut stimulates significant intertemporal substitution in purchases.

Only a few studies analyze the recent German VAT reduction. Fuest et al. (2021) find that total consumption has increased by $0.6 \%$. Fuest et al. (2020) and Montag et al. (2020) use data about price changes in supermarkets and fuel stations to estimate the VAT pass-through of the German VAT cut. Fuest et al. (2020) find asymmetric VAT pass-through behavior in supermarkets: about $70 \%$ of the VAT cut in Germany was passed on to consumers, but the VAT readjustment effect on prices in January 2021 was only about half that size. Montag et al. (2020) find heterogeneous pass-through estimates for different fuel types between $40 \%$ and $84 \%$. However, both studies concentrate on specific non-durable consumption goods. Beck et al. (2021) use scanner data provided by GfK, containing information on prices and quantities of more than 100 million transactions. They find that $86 \%$ of the tax decrease was passed through to consumers with a pass-through rate of $96 \%$ for slow-moving (mainly nondurable) goods and $76 \%$ for fast-moving products (mainly durables). The temporary tax cut led to stabilization effects of about $0.3 \%$ of the GDP, corresponding to $0.6 \%$ of aggregate consumption. Bachmann et al. (2021) use survey and scanner data on households' all-consumption expenditures and their perceived pass-through of the tax change into prices to quantify the VAT effect. They found that the temporary VAT cut in Germany led to a substantial relative increase in durable goods spending of $36 \%$ for individuals with a high perceived pass-through. Spending on semi- and non-durable goods also increased. Due to their baseline estimates, the VAT cut increased aggregate consumption spending by 34 billion euros or $2 \%$ and reduced fiscal revenue by 7 billion euros, which translates to a VAT multiplier close to 5.

These studies use different methodologies rely on survey data rather than official National Account Statistics. Furthermore, they concentrate on the impact effects in 2020. In contrast to these studies, we contribute to this strand of literature by using a dynamic model approach matched to German data and simulate a specific sectoral lockdown shock to match the observed National Account Statistic data in Germany between 2Q2020 to 2Q2021, similar to the methodology used in Christiano et al. (2015). In particular, we consider dynamic effects, such as those due to possible front loading of consumption and spillover effects on other macroeconomic aggregates. This provides a more comprehensive estimate of budgetary effects. We run counterfactual analyses to estimate the 
effects of the German VAT rate reduction in July 2020, the readjustment in the subsequent quarters in 2021 and disentangle specific channels, for example lockdown, ZLB, durable goods, and role of the pass-through. When we explicitly consider durable consumption goods in the model, our estimates confirm the results of the survey studies, by Bachmann et al. (2021), of high substitution effects in case we explicitly consider durable consumption goods in the model. In our most preferred estimation, we estimate a GDP effect of 32 bn euros in 2020. However, we find a higher fiscal revenue shortfall of close to 18 bn euros in 2020, such that the short-term multiplier is 1.8 . Over the medium term, the cumulative VAT multiplier reduces below 1 due to missing durable goods consumption that is shifted toward 2020. Furthermore, we find that the lockdown shock has reduced the effectiveness of the VAT instrument. Without the lockdown situation and the resulting consumption constraints, a 1 euro VAT revenue reduction in Germany would have increased GDP by roughly 2 euros.

The paper is organized as follows: In Section 2, we start with a short empirical motivation of our research objective. In Section 3, we briefly explain the DSGE model setup with a focus on the lockdown shock, the durable investment channel, the imperfect pass-through and how we detect relevant model parameters. In Section 4, we apply the model to the specific case of Germany and run policy experiments. We then evaluate the VAT reduction using calculated GDP multipliers. Finally, Section 5 concludes.

\section{Empirical Motivation}

Figure 1 depicts the quarter-to-quarter growth rates of different consumption goods in Germany from 4Q2019 to 2Q2021: expendable, short-lived, long-lived and services. These stylized patterns show that durable goods, which are defined as short- and long-lived goods, were strongly affected by the lockdown shocks that occured in the second and fourth quarters of $2020 .^{2}$ The demand for long-lived goods was reduced cumulatively by almost $15 \%$ in 2Q2020 compared to 4Q2019. When long- and short-lived goods are combined, the durable goods decrease by $14 \%$. The non-durable goods consumption, expendable goods, such as food and other necessities, remained almost constant. In total, non-durable goods decreased by $11 \%$, because the service sector, that is for example, hotels and restaurants, transport services, was strongly affected (-17\%). Consumer durable (short- and long-lived) goods were more affected during the first lockdown than non-durable goods (expendables and services), because production capabilities were also closed.

In 3Q2020, all consumption components indicate a strong catch-up growth, but the increase for consumer durable goods was much larger than that for all other categories. Demand for long-lived goods increased markedly, by almost $28 \%$ compared to the previous quarter. Thus, the loss of total durable goods in the first two quarters 2020 was compensated for in 3Q2020. In contrast, the recovery of non-durable consumption was much weaker. Two major aspects lead to the strong overshooting of durable consumption relative to non-durable goods. First, the recovery process combined with forced savings leads to this V-shaped pattern. Second, the VAT rate reduction supports this development via intertemporal substitution that speeds the recovery process. In the last quarter

\footnotetext{
${ }^{2}$ Consumer durable goods include furniture and household appliances (including kitchen equipment), personal transport equipment, recreational and entertainment goods (including computers and communications equipment), other goods such as jewelry, clocks and watches, and therapeutic medical appliances and equipment. See Casalis and Krustev (2020) for a detailed description.
} 
of 2020, when the pandemic pushed Germany into a second lockdown, both durable and non-durable goods consumption decreased again. The demand for long-lived goods was less affected. However, when the lockdown was extended 1Q2021, demand for short- and especially long-lived goods reduced strongly, which could have been indirectly provoked by the intertemporal consumption shift due to the VAT policy.
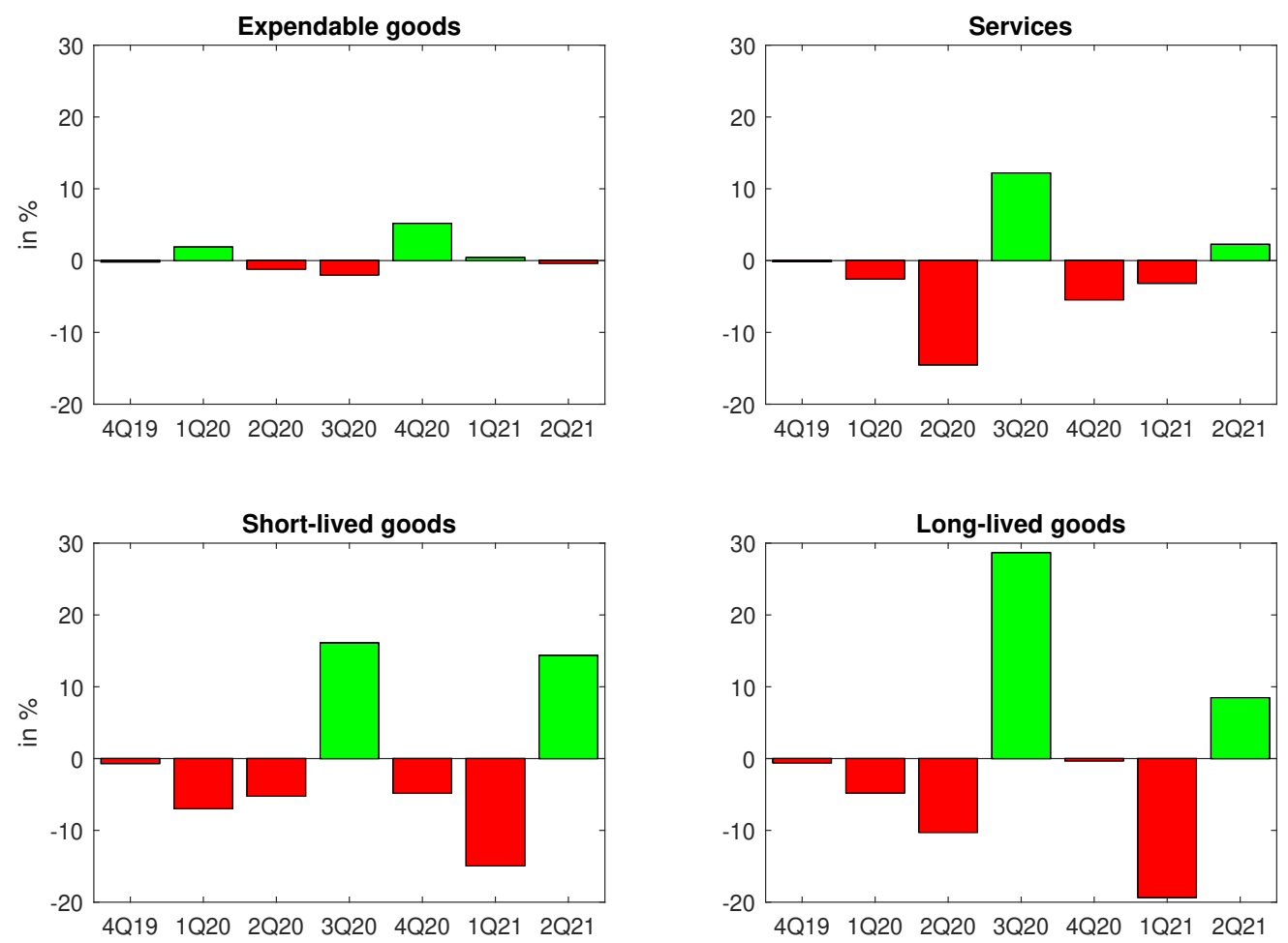

Figure 1: Real consumption by durableness and the COVID-19 pandemic, quarterly q-o-q growth rate, 4Q2019:2Q2021

We want to answer the question that arises from observing the time patterns: to what extent has the VAT rate reduction contributed to the recovery process and the observed pattern in 2020 and 2021 . Therefore, we build a DSGE model that incorporates both durable and non-durable goods consumption and the specific sectoral lockdown in Germany and the ZLB. We can use the advantage of structural modeling and run counterfactual analyses to measure the impact of the state of the economy, for example, the lockdown and the stance of monetary policy, on the effectiveness of the VAT rate reduction.

\section{Modelling the Lockdown}

We extend the model framework of Clemens and Roeger (2022) by adding a second contact-intensive sector. ${ }^{3}$ We consider two infinitely living household types that differ with respect to their savings behavior. Unrestricted

\footnotetext{
${ }^{3}$ See Appendix $\mathrm{D}$ for the model description.
} 
households, also known as Ricardian households, have full access to financial markets; Liquidity-constrained (LC) households, also known as hand-to-mouth consumers, consume their current period income. Both types buy durable and non-durable consumption goods produced by the two sectors $j=1,2$. Sector 1 produces (contactintensive) durable and non-durable goods and is completely closed if a lockdown shock occurs. Sector 2 produces all other private and public consumption and investment goods and is not directly affected by a lockdown shock. We further assume that capital and labor are sector specific. That means in the case of a lockdown, resources cannot be reallocated from sector 1 to sector 2 . All firms are monopolistically competitive, and they set prices subject to convex price adjustment costs.

Firms in sector 1 only sell to consumers and are subject to VAT. Sector 2 firms sell to households, firms and the government. Both sector firms sell to consumers via a retail branch. Sector 2 retailers are also subject to price adjustment costs. Sector 2 retailers pay VAT on their sales.

This sector structure is intended to mimic an economic environment where the lockdown predominantly affects a subset of contact-intensive firms. A lockdown that shuts down contact-intensive transactions closes retail sector 1 and reduces demand for inputs of retail sector 1 to zero. This also affects sector 2 directly via sales of investment goods to sector 1 . Sector 2 is also indirectly affected by a loss of income in sector 1 but possibly benefits from substitution effects and from higher government demand.

\subsection{The Sectoral Lockdown}

A sectoral lockdown is a regulatory measure that closes certain contact-intensive businesses (that provide consumer goods and services) over a certain period; it is a quantity constraint imposed on both consumers and producers. Such a measure is difficult to capture in a macroeconomic framework because it affects different sectors asymmetrically. By imposing restrictions on consumers and producers simultaneously, it is both a demand and a supply constraint.

If only the demand side is emphasized, the disinflationary impact is likely to be overestimated because the supply reduction is overlooked. If only the supply side is stressed and the restrictions imposed on factor demand receive focus, the inflationary impact is likely to be overestimated because restrictions on factor demand act like a positive markup shock. Modeling the lockdown as a combination of a supply and demand shock is inadequate because it misses the sector-specific nature of a lockdown.

Especially in an environment with limited factor mobility, constraints imposed on supply and demand in one sector will only marginally affect factor markets in the remaining sectors and then only via income and substitution effects through demand spillovers. Thus, it is likely that the macro effect will be larger than the initial sectoral shock. This has also been shown by Guerrieri et al. (2020). Adopting a purely aggregate perspective would miss the fact that the sectors are affected differently by the lockdown. It would also be difficult to capture factor immobility across sectors. A purely macroeconomic perspective assumes a high degree of factor mobility across sectors.

Finally, the analysis of certain policy measures, such as VAT rate reductions, will affect lockdown and non- 
affected sectors differently. Because no production takes place in a lockdown sector, the VAT policy is ineffective for these sectors during the lockdown. Whether it stabilizes other sectors depends on whether there are negative or positive spillovers from the lockdown to these sectors.

In this paper, we take the sector-specific nature of a lockdown into account by dividing the economy into one sector that is directly affected by the lockdown (sector 1 ) and another sector that is only indirectly affected by the lockdown via demand and income linkages (sector 2). The lockdown in sector 1 is implemented as a full close down of production over a pre-specified period $t$. This makes firms and households subject to quantity constraints. In the lockdown period, the output of sector one is restricted to zero.

$$
Y_{t}^{1}=0
$$

The production lockdown implies zero demand for labor input in sector 1 and period $t$.

$$
L_{t}^{1}=0
$$

We further assume that labor is immobile across the two sectors. Capital is idle in period $t$, and we assume that firms in sector 1 reduce their investment to zero. This can be regarded as a lower bound on investment in the presence of capital mobility restrictions and leads to a reduction of capital stock.

$$
K_{t}^{1}=(1-\delta) K_{t-1}^{1}
$$

Zero investment would be optimal in the absence of adjustment costs and capital immobility. With adjustment costs, investment would remain positive. However, because of liquidity constraints, firms directly affected by the lockdown postpone their investment plans.

It is assumed that sector 1 produces consumer durable goods $I D_{t}^{1}$ and non-durable goods $N D_{t}^{1}$. Therefore, a quantity constraint on household decisions for durable and non-durable goods applies in period $t$ :

$$
I D_{t}^{1}=N D_{t}^{1}=0
$$

All other demand and savings decisions of the household are subject to an intertemporal budget constraint. The household receives zero wage and capital income from sector 1 :

$$
\begin{aligned}
W_{t}^{1} L_{t}^{1} & =0, \\
r_{t}^{K} K_{t}^{1} & =P_{t}^{1} Y_{t}^{1}-W_{t}^{1} L_{t}^{1}=0 .
\end{aligned}
$$

The loss of income, insofar as it is not compensated by government transfers, will have a direct negative impact on the level of consumption, especially for LC households. However, the net effect on unrestricted sectors depends on how households reallocate spending toward goods offered by the unrestricted sector. As shown by Guerrieri et al. (2020), the degree of substitutability in household preferences between sector 1 and sector 2 goods matters for the spillover effect. They also point out that under the assumption of an elasticity of substitution 
smaller than 1 (complementarity) between sector 1 and sector 2 goods, the (ideal) CPI goes to infinity when the demand for good 1 goes to zero. To avoid this problem, we follow a slightly different approach and assume a missing market for sector 1 goods in the lockdown period. For non-durable goods, this implies that households cannot purchase sector 1 goods during the lockdown period, and we set $N D_{t}^{1}$ and the price for non-durable goods $P_{t}^{N, 1}$ to zero:

$$
P_{t}^{N} N D_{t}=\left(\gamma^{N, 2}\left(P_{t}^{N, 2}\right)^{1-\sigma^{N}}\right)^{\frac{1}{1-\sigma^{N}}}\left(\left(\gamma^{N, 2}\right)^{\frac{1}{\sigma^{N, 2}}}\left(N D_{t}^{2}\right)^{\frac{\sigma^{N}-1}{\sigma^{N}}}\right)^{\frac{\sigma^{N}}{1-\sigma^{N}}}=\left(P_{t}^{N, 2}\right) N D_{t}^{2} .
$$

For durable goods, we take into account that investment on durable goods $I D_{t}$ from sector 1 is restricted to zero, which implies

$$
D_{t}^{1}=(1-\delta) D_{t-1}^{1}>0 .
$$

In the absence of consumption opportunities for good 1, households would shift consumption toward good 2 . This is especially the case for LC households that would spend their entire disposable income in the lockdown period on good 2 with standard preferences. To prevent this from happening, we also introduce an upper bound for the period consumption of good 2:

$$
C_{t}^{2} \leq \bar{C}_{t}^{2}
$$

which is binding in the lockdown period and creates forced savings $F S_{t}$.

Guerrieri et al. (2020) assume that prices are either fully flexible or fixed. Here, we consider the case where firms and workers are setting prices subject to price and wage adjustment costs. Because the market is closed for sector 1 goods in $t=1$, there is no price quoted in the lockdown period. Therefore, the question arises of how firms in sector 1 are setting their prices in the period following the lockdown. To illustrate this, consider the profit $P R_{t}(i)$ maximization problem of a firm $i$ that transforms an intermediate good $Y_{t}^{I, j}$ priced at $P_{t}^{I, j}$ into a final good subject to a linear technology and quadratic price adjustment costs after the market is reopened in $t=2$ :

$$
P R_{t}(i)=E_{t} \sum_{t=2}^{\infty}(\beta)^{t-2}\left(\left(\frac{P_{t}^{1}(i)}{P_{t}^{1}}\right) Y_{t}^{1}(i)-\frac{P_{t}^{I, 1} Y_{t}^{I, 1}(i)}{P_{t}^{1}}-\frac{\gamma^{P}}{2} Y_{t}\left[\frac{P_{t}^{1}(i)}{P_{t-1}^{1}(i)}-1\right]^{2}\right) .
$$

Optimal price setting implies that in period 2, the firm only takes costs for changed prices between $t=3$ and $t=2$ into account,

$$
P_{2}^{1}=\left(1+\mu^{P}+\gamma^{P} \beta\left(E_{2} \pi_{3}^{1}\right)\right) P_{2}^{I, 1},
$$

while in all subsequent periods $t>2$, the firm considers both an expected cost from the next period price adjustment and a price adjustment between the current and the previous period.

$$
P_{t}^{1}=\left(1+\mu^{P}+\gamma^{P}\left(\beta\left(E_{t} \pi_{t+1}^{1}\right)-\pi_{t}^{1}\right)\right) P_{t}^{I, 1}
$$

To implement the lockdown constraints, we use the nonlinear solution procedure in Dynare to solve the model 

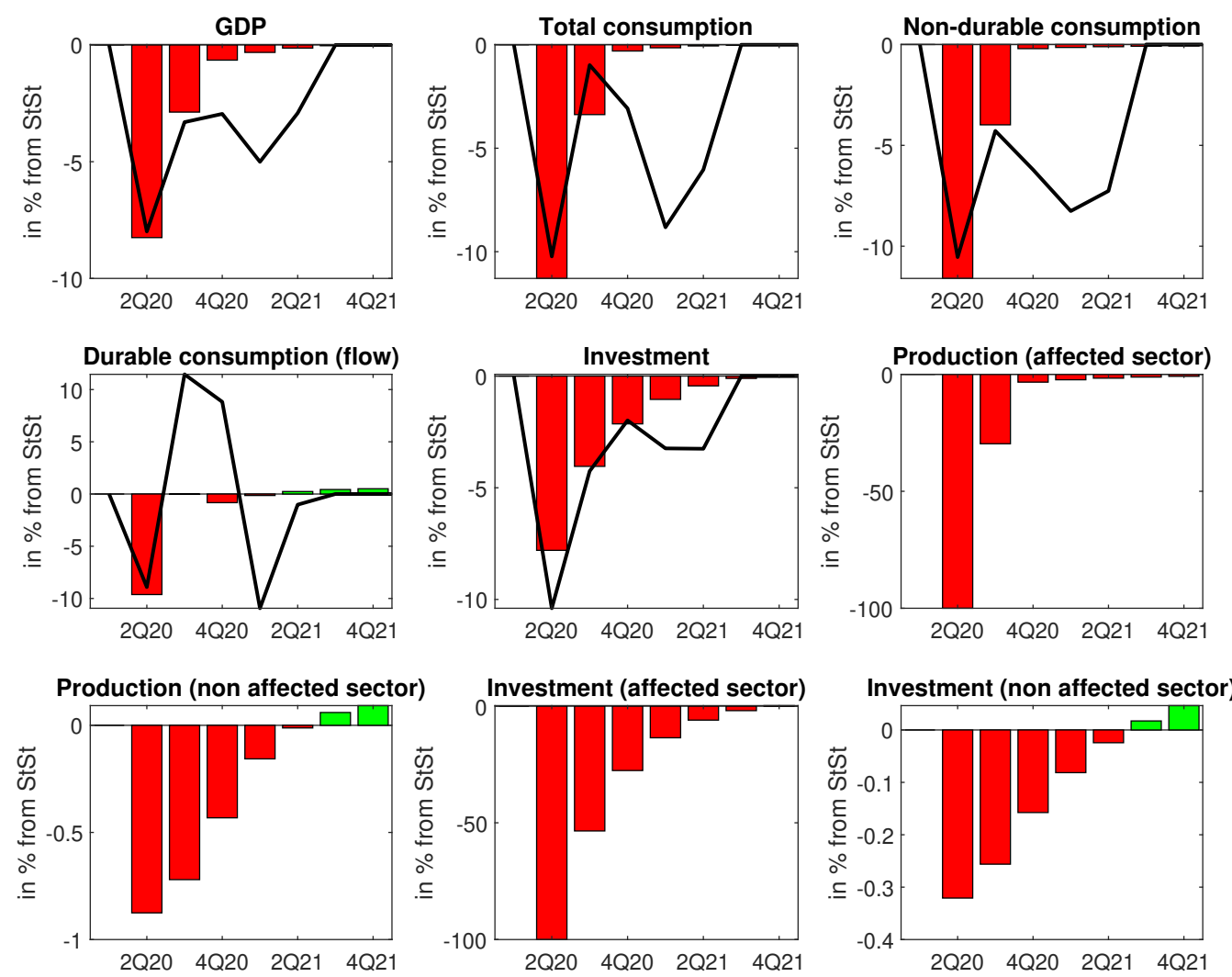

Reaction to Lockdown Shock in 2Q20 - Actual Series (mean)

Figure 2: Impulse response to the unexpected lockdown in 2Q20

in each period subject to the lockdown and other policy shocks occurring in the current period and its expected path. These simulations are carried out under a perfect foresight assumption in each period. The expectation of shocks and policies is revised with new information in the following period. This allows us to solve the model with the production of the contact-intensive consumption-goods-producing sector exactly set to zero and properly constrain both demand for durable and non-durable goods and the CPI.

Figure 2 depicts the reaction of aggregate and sector-specific variables due to the lockdown situation only in 2 Q2020. As can be seen, the first lockdown shock reduces GDP by $8 \%$, consumption by $11 \%$ and investment by $6 \%$. Durable and non-durable goods consumption are both negatively affected by 10 and $11 \%$. Altogether, our lockdown shock matches the actual development of the main aggregates in 2Q2020 quite well. We abstract here from subsequent lockdown shocks and fiscal stabilization measures, such as transfers and the VAT policy, to show that our model can replicate the actual development due to the lockdown. Furthermore, we can analyze the reaction of unobservable variables, such as sectoral outputs and investments, due to the lockdown. We find that, by definition, the lockdown shock reduces production and investment in the affected sector by $100 \%$. The production in the non-affected sector is reduced by about $1 \%$. Even investment in the non-affected sector is indirectly affected, although to a lesser extent. This is an important result because it legitimates broad policy 
measures, such as interest rate cuts or VAT reductions, that stabilize the demand in the indirectly affected sector. The strong reduction in durable goods consumption provides further arguments in favor of a VAT reduction that stimulates demand for durable goods more strongly than demand for non-durable goods. The German VAT policy is modeled as $-3 \mathrm{pp}$ reduction of the average VAT rate. Simulating the pure VAT shock yields a counteracting impulse response pattern compared to the lockdown shock. ${ }^{4}$

\subsection{Durable Consumption in the Utility Function}

Durable goods are explicitly considered in our model, which makes the effects of a VAT rate reduction significantly different from a model without durable goods. In the following, we describe the key equations to understand the durable goods channel and explain the parameterization of the durable adjustment cost parameter in more detail.

The model begins with the utility function of two household types of which a fraction $s^{L}$ is liquidity constrained and a fraction $1-s^{L}$ is a Ricardian household that owns capital and firms. The liquidity status of household types is marked by the superscript $l$. Both household types $l=R, L$ optimize private consumption and leisure according to the following utility function: $U_{t}=E_{0} \sum_{t=0}^{\infty} e_{t}^{d} \beta^{t}\left(\log \left(C_{t}^{l}\right)-\omega^{j} \frac{\sum_{j=1}^{2}\left(L_{t}^{j}\right)^{1+\rho}}{1+\rho}\right)$. Both household types supply specific labor to both sectors $j$ (affected, non-affected) and consume non-durable goods $P^{N} N D^{l, j}$ and durable goods $P^{D, l} D^{l, j}$ produced by both sectors. Preferences for durable and non-durable goods are specified as a constant elasticity of subtitution (CES) utility function:

$$
c_{t}^{l}=\left[\left(\psi^{N, l}\right)^{\frac{1}{\sigma^{N D}}}\left(N D_{t}^{l}\right)^{\frac{\sigma^{N D}-1}{\sigma^{N D}}}+\left(\psi^{D, l} \psi^{D, l, 1}\right)^{\frac{1}{\sigma^{N D}}}\left(D_{t}^{l, 1}\right)^{\frac{\sigma^{N D}-1}{\sigma^{N D}}}+\left(\psi^{D, l} \psi^{D, l, 2}\right)^{\frac{1}{\sigma^{N D}}}\left(D_{t}^{l, 2}\right)^{\frac{\sigma^{N D}-1}{\sigma^{N D}}}\right]^{\frac{\sigma^{N D}}{\sigma^{N D}-1}}
$$

where $\psi^{N, l}$ and $\psi^{D, l}$ denote the consumption shares of durable and non-durable goods. $\psi^{D, l, 1}$ and $\psi^{D, l, 2}$ measure the sectoral production share of durable goods and $\sigma^{N D}$ is the elasticity of intratemporal substitution between durable and non-durable goods. The total durable and non-durable consumption baskets can be composed according to the sectoral production:

$$
\begin{gathered}
D_{t}^{l}=\left[\left(\psi^{D, l, 1}\right)^{\frac{1}{\sigma^{D}}}\left(D_{t}^{l, 1}\right)^{\frac{\sigma^{D}-1}{\sigma^{D}}}+\left(\psi^{D, l, 2}\right)^{\frac{1}{\sigma^{D}}}\left(D_{t}^{l, 2}\right)^{\frac{\sigma^{D}-1}{\sigma^{D}}}\right]^{\frac{\sigma^{D}}{\sigma^{D}-1}}, \\
N D_{t}^{l}=\left[\left(\psi^{N, l, 1}\right)^{\frac{1}{\sigma^{N}}}\left(N D_{t}^{l, 1}\right)^{\frac{\sigma^{N}-1}{\sigma^{N}}}+\left(\psi^{N, l, 2}\right)^{\frac{1}{\sigma^{N}}}\left(N D_{t}^{l, 2}\right)^{\frac{\sigma^{N}-1}{\sigma^{N}}}\right]^{\frac{\sigma^{N}}{\sigma^{N}-1}},
\end{gathered}
$$

where $\psi^{N, l, 1}, \psi^{N, l, 2}$ are the sectoral production shares for non-durable goods and $\sigma^{D}=\sigma^{N}$ are the sectoral substitution elasticities.

The Ricardian household has access to one-period private domestic bonds $B_{t}$ that pay 1 unit of the national currency in $t+1$ and sell at price $R_{t}^{-1}$. Additionally, the Ricardian household can rent out new capital to firms $P_{t}^{I} I_{t}$ and receives after-tax wage income $\left(1-\tau^{\mathrm{W}}\right) W_{t} L_{t}$, capital income from renting to firms $R_{t}^{k} K_{t-1}$, transfers

\footnotetext{
${ }^{4}$ See Figure 5 in the Appendix for the 'plain' VAT rate shock.
} 
from the government $Z_{t}^{R}$ and profits from firms $P R_{t}$. The flow budget constraint for the Ricardian household is

$$
\begin{aligned}
(1+ & \left.\tau_{t}^{V A T}\right)\left(P_{t}^{N, 1} N D_{t}^{R, 1}+P_{t}^{N, 2} N D_{t}^{R, 2}+P_{t}^{D, 1} I D_{t}^{R, 1}+P_{t}^{D, 2} I D_{t}^{R, 2}\right)+P_{t}^{I} I_{t}+B_{t}=R_{t-1} B_{t-1}+R_{t}^{k} K_{t-1} \\
& +\left(1-\tau^{W}\right)\left(L_{t}^{2} W_{t}^{2}+L_{t}^{1} W_{t}^{1}\right)-P_{t}^{I} I_{t}\left(1+\frac{\gamma^{K}}{2}\left(\frac{I_{t}}{K_{t}}-\frac{\bar{I}}{\bar{K}}\right)^{2}\right)-P_{t}^{I} \frac{\gamma^{I}}{2}\left(I_{t}-I_{t-1}\right)^{2}+Z_{t}^{R}+P R_{t}
\end{aligned}
$$

The Ricardian household buys non-durable goods $N D_{t}^{R, j}$ and new durable goods consumption $I D_{t}^{R, j}$ at net prices $P_{t}^{N, j}$ and $P_{t}^{D, j}$. This household pays value-added tax for the rent of existing durable goods and for the purchase of new durable goods. $P_{t}^{N, j}$ and $P_{t}^{D, j}$ are the net consumer prices of non-durable and durable goods set by the firms. Furthermore, the household holds the aggregate capital stock $K_{t}$ and takes new investments $I_{t}$. Capital accumulation comes along with capital adjustment costs $\frac{\gamma^{K}}{2}\left(\frac{I_{t}}{K_{t}}-\frac{\bar{I}}{\bar{K}}\right)^{2}$ and with investment adjustment costs $\frac{\gamma^{I}}{2}\left(I_{t}-I_{t-1}\right)^{2}$. The aggregate capital stock and aggregate investment is used in both sectors, $K_{t}=$ $K_{t}^{1}+K_{t}^{2}$ and $I_{t}=I_{t}^{1}+I_{t}^{2}$, and the sectoral capital stocks $K_{t}^{j}$ evolve according to the following usual definition $K_{t}^{j}=(1-\delta) K_{t-1}^{j}+I_{t}^{j}$, where $\delta$ is the rate at which the capital stock depreciates. Similarly, the stock of durable goods $D_{t}^{R}$ produced in both sectors $j=1,2$ is determined by the consumption of the Ricardian household $D_{t}^{R, j}=\left(1-\delta^{D}\right) D_{t-1}^{R, j}+I D_{t}^{R, j}$, where $I D_{t}^{R, j}$ denotes the Ricardian household purchases of new durable goods in sector $j . P_{t}^{D, j}$ is the durable goods price in sector $j$ relative to the aggregate durable price. ${ }^{5}$

The LC household has identical preferences for durable and non-durable goods as the unconstrained household. With choosing between durable and non-durable goods, the LC household must also solve an intertemporal maximization problem under a sequence of period budget constraints

$$
F S_{t}+\left(1+\tau_{t}^{V A T}\right)\left(P_{t}^{N, 1} N D_{t}^{L, 1}+P_{t}^{N, 2} N D_{t}^{L, 2}+P_{t}^{D, 1} I D_{t}^{L, 1}+P_{t}^{D, 2} I D_{t}^{L, 2}\right)=\left(1-\tau^{W}\right)\left(L_{t}^{2} W_{t}^{2}+L_{t}^{1} W_{t}^{1}\right)+Z_{t}^{L}
$$

where $W_{t}^{1} L_{t}^{1}$ and $W_{t}^{2} L_{t}^{2}$ is the labor income in both sectors and $Z_{t}^{L}$ is the transfer income of the LC household. The budget constraint implies that expenditure on non-durable and new durable goods is constrained by current net income. The LC household also accumulates durable goods:

$$
D_{t}^{L, j}=\left(1-\delta^{D}\right) D_{t-1}^{L, j}+I D_{t}^{L, j}
$$

$I D_{t}^{L, j}$ denotes the LC household purchases of new durable goods produced in sector $j$.

The first-order conditions of the optimization problem give the intertemporal consumption and investment Euler equations, labor supply, optimal durable and non-durable goods consumption for both household types. ${ }^{6}$ Here, we focus only on how the demand for durable and non-durable goods responds to actual and expected changes in value-added taxes. Therefore, we derive the definition of the consumer price deflator, which consists

\footnotetext{
${ }^{5}$ Note that by assumption durable goods are produced under perfect competitive markets and according to a linear production technology. Thus, the aggregate durable good price $P^{D}$ is equal to the producer price $P^{Y}$

${ }^{6}$ See the model description in Appendix D.
} 
of the non-durable price and the service price for durable goods: ${ }^{7}$

$$
P_{t}^{C, l}=\left(\bar{\psi}^{N, l}\left(\left(1+\tau_{t}^{V A T}\right) P_{t}^{N}\right)^{1-\sigma^{N D}}+\bar{\psi}^{D, l}\left(\left(1+\tau_{t}^{V A T}\right) P_{t}^{D, l}\right)^{1-\sigma^{N D}}\right)^{\frac{1}{1-\sigma^{N D}}}
$$

where $\bar{\psi}^{N, l}$ and $\bar{\psi}^{D, l}$ are the consumption shares for durable and non-durable goods consumption. $P_{t}^{D, l}$ is a function of $R_{t}^{D, l}$ which can be regarded as a rental price for durable goods that must be considered as an additional price component for new durable goods. $R_{t}^{D, l}$ differs between household types, because the access to financial markets real market rates determines the underlying opportunity costs: For the Ricardian household the rental rate is $R_{t}^{D, R, j}=\delta^{D}+r_{t}-\left(E_{t} \pi_{t+1}^{D, j}-E_{t} \pi_{t+1}^{Y, j}\right)-\gamma^{D}\left(\frac{E_{t} I D_{t+1}^{R, j}}{D_{t}^{R, j}}-\frac{I D_{t}^{R, j}}{D_{t-1}^{R, j}}\right)-E_{t} \Delta \tau_{t+1}^{V A T}$. Without access to financial markets, the marginal rate of substitution between the current and future consumption of the LC household is not given by the market interest rate but by the rate of time preference, the expected growth rate of LC household's consumption plus the expected growth rate of the LC households's CPI $R_{t}^{D, L, j}=\delta^{D}+E_{t} \pi_{t+1}^{C, L}+E_{t} g_{t+1}^{C, L}+\frac{1}{\beta}-$ $1-E_{t} \pi_{t+1}^{N, j}-E_{t} \pi_{t+1}^{Y, j}-\gamma^{D}\left(\frac{E_{t} I D_{t+1}^{L, j}}{D_{t}^{L, j}}-\frac{I D_{t}^{L, j}}{D_{t-1}^{L, j}}\right)-E_{t} \Delta \tau_{t+1}^{V A T}$. Factors that increase the ratio of durable to nondurable goods in $t$ are the expected increase in VAT and the expected decline of LC household's consumption in $t+1$. These factors are mitigated by the expected increase in the consumer price deflator and the limited VAT pass-through.

A temporary reduction of the value-added tax rate leads to two effects on consumption: First, it leads to an increase of current consumption because of an expected consumer price inflation effect according to the Euler equation of the Ricardian household $\frac{E_{t} C_{t+1}^{R}}{C_{t}^{R}}=\beta\left(1+i_{t}\right) \frac{P_{t}^{C, R}}{E_{t} P_{t+1}^{C, R}}$. Second, there is also a relative demand effect at work, as can be seen if we put the first-order conditions for non-durable goods demand $N D_{t}^{l}=\bar{\psi}^{N, l} C_{t}^{l}\left(\frac{\left(1+\tau_{t}^{V A T}\right) P_{t}^{N}}{P_{t}^{C, l}}\right)^{-\sigma^{N D}}$ and durable goods demand $D_{t}^{l}=\bar{\psi}^{D, l} C_{t}^{l}\left(\frac{\left(1+\tau_{t}^{V A T}\right) P_{t}^{D, l} R_{t}^{D, l}}{P_{t}^{C, l}}\right)^{-\sigma^{N D}}$ together to get the relative demand function:

$$
\left(\frac{\bar{\psi}^{D, l}}{\bar{\psi}^{N, l}}\right)^{\frac{1}{\sigma^{N D}}}\left(\frac{N D_{t}^{l}}{D_{t}^{l}}\right)^{\frac{1}{\sigma^{N D}}}=\frac{P_{t}^{D, l}}{P_{t}^{N}} R_{t}^{D, l}
$$

In the case of a temporary VAT reduction in period $t$, the ratio of durable to non-durable goods increases because the service price for durable goods declines in anticipation of a VAT increase in $t+1$. This, however, hinges on the nominal interest rate reaction and a limited expected inflation differential between the durable goods price and the price of final goods (both excluding VAT) and limited variation between the durable and non-durable goods price in $t$. At the current juncture, with a ZLB for the nominal interest rate, $i_{t}$ remains constant. Because of limited pass-through, there will be an expected decline of $E_{t} \pi_{t+1}^{D}$. This effect will be smaller than the expected VAT increase, except in the case of zero pass-through. The relative price between durable and non-durable goods is likely to be small in the case without adjustment costs for durable goods because both goods are affected by the same VAT shock. With adjustment costs for durables, $P_{t}^{D}$ includes adjustment costs and thus increases relative to $P_{t}^{N}$. Note, that even a small growth differential between the stock of durable and non-durable goods will lead

\footnotetext{
${ }^{7}$ For clarity, we do not display the sectoral demand functions.
} 
to large differences in new durable goods consumption.

\subsection{VAT Pass-Through to Consumer Prices}

Our model consists of price adjustment costs for intermediate and retail producers. Thus, the question arises of whether price adjustment costs associated with changing VAT might be smaller than price adjustment costs arising from changes in prices.

We use a New Keynesian Phillips curve for prices, assuming firms face quadratic costs of adjusting prices (including VAT). The sales price for the firm is $P_{t}^{S}(i)=\left(1+\tau_{t}^{V A T}\right) P_{t}^{\text {ret }}(i)$. The firm faces quadratic costs for adjusting prices. Price adjustment costs associated with changing VAT might be smaller than price adjustment costs arising from changes in input prices. Therefore, we write adjustment cost as a weighted average of the sales price and the price excluding VAT, with weights $\gamma^{V A T}$ and $1-\gamma^{V A T}$ respectively:

$$
\text { AdjCosts }=\frac{\gamma^{P}}{2}\left[\frac{\left(P_{t}^{S}(i)\right)^{\gamma^{V A T}}\left(P_{t}^{r e t}(i)\right)^{1-\gamma^{V A T}}}{\left.\left(\Pi_{t-1}^{\text {ret }}\right)^{s^{P}}\left(\Pi_{t}^{r e t, T}\right)^{1-s^{P}} P_{t}^{S}(i)\right)^{\text {VAT }}\left(P_{t}^{\text {ret }}(i)\right)^{1-\gamma^{V A T}}}-1\right]^{2} .
$$

Retail firm $i$ maximizes profits $P R_{t}^{r e t}$

$P R_{t}^{r e t}=P_{t}^{r e t}(i)\left(1+\tau_{t}^{V A T}\right) Y_{t}^{C}(i)-P_{t} Y_{t}-\frac{\gamma^{P}}{2}\left[\frac{P_{t}^{r e t}(i)\left(1+\tau_{t}^{V A T}\right)^{\gamma^{V A T}}}{\left(\Pi_{t-1}^{r e t}\right)^{s^{P}}\left(\Pi_{t}^{r e t, T}\right)^{1-s^{P}} P_{t-1}^{r e t}(i)\left(1+\tau_{t-1}^{V A T}\right)^{\gamma^{V A T}}}-1\right]^{2}-\tau_{t}^{V A T} P_{t}(i) Y_{t}(i)$

subject to a simple linear production technology

$$
Y_{t}^{C}(i)=Y_{t}(i)
$$

and the demand equation

$$
Y_{t}^{C}(i)=\left(\frac{P_{t}^{r e t}(i)\left(1+\tau_{t}^{V A T}\right)}{P_{t}^{r e t}\left(1+\tau_{t}^{V A T}\right)}\right)^{-\eta^{P}}
$$

where the VAT is not relevant because competitors face the same VAT. Considering that the firm knows that all competitors also pay VAT, the price setting problem simplifies, and VAT only appears in the price adjustment cost term. The problem firm $i$ faces when there is an exogenous change in $\tau_{t}^{V A T}$ is how to set the price $P_{t}(i)$ such that the price adjustment cost for $P_{t}(i)\left(1+\tau_{t}^{V A T}\right)$ is minimized.

We then can derive the price-setting function, from the profit maximization decision of the retail firm:

$$
P_{t}^{r e t}=1+\mu_{t}^{r e t}+\gamma^{P, r e t}\left(\beta\left(E_{t} \pi_{t+1}^{r e t}+\frac{\gamma^{V A T}}{1+\tau^{V A T}} E_{t} \Delta \tau_{t+1}^{V A T}\right)-\left(\pi_{t}^{r e t}+\frac{\gamma^{V A T}}{1+\tau^{V A T}} \Delta \tau_{t}^{V A T}\right)\right) .
$$

In the case of $\gamma^{V A T}=1$, price adjustment costs do not depend on the source of the price change. In the case of $\gamma^{V A T}=0$, the firm faces no cost with changed prices due to VAT changes. In all cases in between, the firm faces a positive but smaller cost of price adjustment due to VAT changes. In contrast to other cost shocks, the VAT change is announced by the government such that firms do not have to pay advertise price reductions. Furthermore, firms could have an additional incentive to pass through the VAT if the government asks firms to 
do so as part of the national stabilization policy. However, it is difficult to calibrate or estimate this parameter. To show how the change in VAT translates into consumer price, we can simplify the retail price inflation by taking the logarithm $\left(p^{\text {ret }}=\log \left(P^{r e t}\right)\right)$ and rewriting it:

$$
p_{t}^{r e t}-p_{t-1}^{r e t}=\mu_{t}^{r e t}+\beta\left(E_{t} p_{t+1}^{r e t}-p_{t}^{r e t}\right)+\frac{\beta \gamma^{V A T}}{1+\tau^{V A T}} E_{t} \Delta \tau_{t+1}^{V A T}-\frac{\gamma^{V A T}}{1+\tau^{V A T}} \Delta \tau_{t}^{V A T}+\frac{1}{\gamma^{\prime} \text { ret }} p_{t}^{\text {ret }}
$$

By iterating forward and establish the relationship between retail and consumer prices $p_{t}^{C}=p_{t}^{\text {ret }}+\log \left(1+\tau_{t}^{V A T}\right)=$ $p_{t}^{r e t}+\tau_{t}^{V A T}$ and consumer price inflation $\pi_{t}^{C}=p_{t}^{r e t}-p_{t-1}^{r e t}+\Delta \tau_{t}^{V A T}$, we can express the consumer price inflation as a function of the VAT change

$$
\pi_{t}^{C}=\left(\lambda_{1}-1\right) p_{t-1}^{r e t}+\Delta \tau_{t}^{V A T}+\frac{1}{\lambda_{2}} \sum_{k=0}^{\infty}\left(\frac{1}{\lambda_{2}}\right)^{k}\left(\frac{\gamma^{V A T}}{1+\tau^{V A T}}\left(E_{t} \Delta \tau_{t+1+k}^{V A T}-\frac{1}{\beta} \Delta \tau_{t+k}^{V A T}\right)+\frac{1}{\gamma^{P, r e t}} \mu_{t+k}^{r e t}\right),
$$

where $\lambda_{1} \leq 1$ and $\lambda_{2}>1$ are the characteristic roots of the second-order nonlinear difference equation. ${ }^{8}$

For simplicity and to discuss the intuition of parameter $\gamma^{P, \text { ret }}$, we assume a one-period VAT reduction that returns to the steady-state rate in period $t+1$. Therefore, we can write $\Delta \tau_{t}^{V A T}=-0.01, \Delta \tau_{t}^{V A T}=0.01$ and $\sum_{t=2}^{\infty} \Delta \tau_{t+2+k}^{V A T}=0$. Furthermore, we set $\bar{P}^{r e t}=1$ such that its logarithm is equal to $\log \bar{P}^{r e t}=\bar{p}^{r e t}=0$. We then can simplify Equation (27) to a 2-period problem:

$$
\pi_{t}^{C}=\Phi_{1} E_{t} \Delta \tau_{t+1}^{V A T}+\Phi_{2} \Delta \tau_{t}^{V A T}+\frac{1}{\lambda_{2} \gamma^{P, r e t}} \mu_{t}^{P, \text { ret }}
$$

where we define combined auxiliary parameters $\Phi_{1}=\frac{\left(1-\frac{1}{\beta \lambda_{2}}\right) \gamma^{V A T}}{\lambda_{2}\left(1+\tau^{V A T}\right)}$ and $\Phi_{2}=\left(1-\frac{\gamma^{V A T}}{\beta \lambda_{2}\left(1+\tau^{V A T}\right)}\right)$.

In the next step, we distinguish between the two polar cases. If $\gamma^{V A T}=0$, Equation (28) reduces to:

$$
\pi_{t}^{C}=\Delta \tau_{t}^{V A T}+\frac{1}{\lambda_{2} \gamma^{P, r e t}} \mu_{t}^{P, r e t}
$$

Here, the intuition is straightforward: with $\gamma^{V A T}=0$, firms have lower price adjustment costs due to the VAT change. In this specific case, the VAT change translates one to one into CPI inflation. Comparing $\Delta \tau_{t}^{V A T}=0.01$ with $\mu_{t}^{P, \text { ret }}=0.01$ shows that a one pp reduction of the VAT would reduce CPI inflation by one pp in period $t$, while the markup shock would increase CPI inflation by $0.05 \mathrm{pp}$ in period $t$. Thus, for $\gamma^{V A T}=0$, the effect of VAT reduction directly transmits to the CPI inflation on a one-to-one basis. Note the typical price markup shock translates only $1 / 20$, which corresponds to a Calvo (1983) parameter of 0.8 or roughly $20 \%$ of all firms that can adjust prices immediately.

If $\gamma^{V A T}$ is equal to one, consumer price dynamics is mainly reflected by general sales and intermediate price setting behavior. With our baseline calibration $\beta=0.995$ and $\gamma^{P, \text { ret }}=20$, the characteristic roots become $\lambda_{1}=0.80, \lambda_{2}=1.25, \Phi_{1}=0.16$ and $\Phi_{2}=0.19$. Thus, a one pp reduction of the VAT leads now to a $0.03 \mathrm{pp}$ reduction of the $\mathrm{CPI}$ inflation in period $t$. The price dynamics in reaction to the VAT change mainly depends on the price adjustment cost parameter $\gamma^{P, r e t}$ that is also the relevant coefficient for $\lambda_{2}$.

\footnotetext{
${ }^{8}$ See Appendix $\mathrm{C}$ for the detailed derivation and the solution of the roots.
} 


\subsection{Matching the Model to the Data}

The specific situation under which the German government decides to reduce the VAT matters. Thus, to analyze adequately how the VAT reduction has affected the German macroeconomy, we consider three specific shocks: a sectoral lockdown shock, a savings shock and a government transfer shock. The sectoral lockdown shock occurs as described in 3.1. For the savings shock we set forced savings and time preference shocks for LC and Ricardian households such that the model savings rate matches the observed savings rate. Finally, we include transfer shocks according to the German government's stabilization policy (see Table 3 in the Appendix). We assume that all shocks are unexpected in the period when they take place. ${ }^{9}$ Furthermore, we consider specific policy states as the ZLB and the temporary offset of the German debt brake. The sectoral lockdown and the policy states feature the nonlinear effects of a VAT rate reduction. Thus, we simulate the nonlinear model for different counterfactual scenarios.

To match our simulated series to the observed time-series data, we follow Christiano et al. (2015) and compare the model simulations with empirically estimated "target gaps" of relevant macro variables. Target gaps can be used as a benchmark for our model simulations. They are the empirical counterparts of the model simulations. Data for most macroeconomic variables are available for the whole period between 1Q2020 and 2Q2021; we only have uncertainty regarding the correct empirical "steady state" or trend value. To account for this uncertainty, we follow Christiano et al. (2015) and calculate max-min ranges. Thereby, we compute for each variable of interest the linear trend from date $x \in\{1 \mathrm{Q} 1991, \ldots, 4 \mathrm{Q} 2015\}$ to $1 \mathrm{Q} 2020$. From the last observation onward, the trend growth rate is extrapolated by an 1-order autoregressive $(A R(1))$ process. We then calculate the "target gaps", that is the differences between actual and projected steady-state values at different time horizons. Because their true values are unknown, we construct the min-max range of the computed gaps that should serve as a benchmark for our model predictions.

\subsection{Parameterization}

The empirical validation of our model is provided by setting some parameters such that empirical observations for Germany in the lockdown situation are matched by the theoretical model. The parameters summarized in Table 5 in the Appendix are split into two subsets. The first group consists of parameters that we calibrate either by relying on values commonly used in the literature ${ }^{10}$ or by matching macroeconomic ratios and policy targets ${ }^{11}$. The second group contains lockdown-specific parameters, such as the share of affected sectors, for which a direct empirical counterpart is hard to detect. We set them to match the reaction of output and durable and non-durable goods consumption after the lockdown shock. This second group also includes the relevant parameters $\gamma^{D}$ and

\footnotetext{
${ }^{9}$ The first lockdown and the VAT shock, which was called the surprise feature of the German stimulus package, were not expected. The assumption regarding the second lockdown is discussed because epidemiologists had already warned about a second wave in summer of 2020. However, official economic forecasts from the government, research institutes, and central banks did not include it in their forecasts and projections. We also assume that the savings and almost all transfer shocks are unobserved because they occur due to the lockdown. The German government announced that households and firms could have access to transfers and grants ("Kurzarbeitergeld" and "Überbrückungshilfe") until the end of the year, although, the access was limited to affected households and firms. Thus, these transfers and grants were unobserved, as was the lockdown itself.

${ }^{10}$ See, e.g., Burgert et al. (2020).

${ }^{11}$ See Table 4 in the Appendix.
} 
$\gamma^{V A T}$ that we have described in more detail in the previous subsections.

The time preference factor $\beta$ is set to 0.996 to match a steady-state interest rate of roughly $1.6 \%$. The capital share $\alpha^{K}=0.325$ corresponds to the average capital output ratio of roughly 3 in Germany between 1991 to 2019. The parameter that determines the Frisch elasticity (at the intensive and extensive margin) of total labor volume (supply) $\rho$ is set to 0.5 to match the labor income share. The share of LC households $s^{L}$ is set to 0.28 according to Grabka and Halbmeier (2019). The quarterly depreciation rate for private investments $\delta$ is set to 0.014 similar as in Coenen et al. (2013). For the durables we set the depreciation rate to $\delta^{D}=0.025$ in order to consider higher annual depreciation rates of goods that are bought during the pandemics, such as vehicles and appliances. ${ }^{12}$ We set the steady-state ratios of government consumption per GDP $\bar{G} / \bar{Y}$ and durable (plus semi-durable) goods consumption per total consumption $\psi^{D}$ both to $20 \%$ according to the observed time-series average value.

The second parameter blocks consist of adjustment costs and lockdown parameters. According to the literature, we set price adjustment costs in both sectors to $\gamma^{P, 1}=\gamma^{P, 2}=20 .{ }^{13}$, but we do not consider price indexation $s_{p}=0$. We proceed similarly for wage $\gamma^{W, 1}=\gamma^{W, 2}=120$, investment $\gamma^{I}=75$ and capital adjustment costs $\gamma^{K}=20$. The adjustment cost parameter for durable goods consumption $\gamma^{D}$ is set to 3 to match the relative reaction of durable to non-durable goods consumption due to the lockdown shock. We set the VAT-specific price adjustment cost parameter to $\gamma^{V A T}=0.4$ such that a firm faces a positive but smaller cost of price adjustment due to VAT change than for other price shocks. With $\gamma^{V A T}=0.4$, a one pp cut in the VAT rate would be associated with a $0.6 \mathrm{pp}$ reduction in the CPI inflation rate. Thereby, we match the results of recent empirical studies that estimate an implicit VAT pass-through to prices for different consumption good types between $40-84 \%$, and the perceived pass-through of the households is estimated at $67 \%{ }^{14}$

The non-durable goods consumption per GDP ratio is set to the empirical counterpart of 0.43 . We choose production shares of durable and non-durable goods $\psi^{D, 1}, \psi^{N, 1}$ in the lockdown sector to match the observed GDP path. We choose a low substitution elasticity between durable and non-durable goods of $\sigma^{N D}=\sigma^{N}=0.75$, which is the mean average of empirical estimates. ${ }^{15}$ Finally, we set the inter-sectoral substitution elasticity $\sigma^{D}=\sigma^{N}$ equal to 0.7 to reflect the complementarity between the affected and the non-affected sectors. ${ }^{16}$

Monetary and fiscal policy parameters are set mainly according to the literature. As for the monetary policy rule - if it applies - we set the weight for interest rate smoothing $\phi^{i}$ to 0.9 , the CPI inflation stabilizing weight $\phi^{\pi}$ to 1.5 , and both the output gap target parameter $\phi^{y}$ and the output growth target $\phi^{d y}$ to zero. By the latter, we consider that the central bank does not counteract fiscal policy stimulus effects. In the fiscal sector, we set

\footnotetext{
${ }^{12}$ Monacelli (2009) discusses the heterogeneity between durable goods regarding the depreciation rate. Goods like vehicles have high annual depreciation rates of around 15\%, while long-lived durable goods like housing have much lower rates between $1 \%$ and $3 \%$. He chooses an annual value of $1 \%$ because he mainly focuses on housing. Harmenberg and Öberg (2021) find a quarterly depreciation rate for durable goods of 0.023 for cars, furniture, and appliances.

${ }^{13}$ See Burgert et al. (2020).

${ }^{14}$ See Montag et al. (2020), Fuest et al. (2020), Beck et al. (2021) and Bachmann et al. (2021).

${ }^{15}$ See Ogaki and Reinhart (1998), Pakoš (2011), Barsky et al. (2019) and McKay and Wieland (2021) who find values between 0.5 and close to one.

${ }^{16}$ Rotemberg and Woodford (1996) estimate a value of 0.7 for the elasticity of substitution between the capital-labor and the intermediate input bundles. Baqaee and Farhi (2020), Atalay (2017) find elasticity of substitution across intermediates and value added to be between 0.4 and 0.8 in the USA. Hinterlang et al. (2020) set the substitution elasticity for goods produced in the different sectors to 0.5 for consumption and investment baskets.
} 
the steady-state government debt-to-GDP ratio $\bar{b} / \bar{y}$ equal to $60 \%$ on an annual basis. The steady-state VAT rate $\bar{\tau}^{\text {vat }}$ is equal to 0.175 , which matches the average VAT rate. ${ }^{17}$ The parameter $\phi_{b y}$ captures the strength of the reaction of lump-sum taxes to deviations of the debt-to-GDP ratio from the target and is set to 0.63 . The parameter that accounts for issuing new debt $\phi_{b}$ is set to 0.06 .

\section{Results}

We conduct a main policy experiments In the baseline experiment, we simulate the first lockdown shock in 2Q2020, the VAT reduction between 3Q2020 and 4Q2020, the second lockdown shock in 4Q2020 and the third lockdown shock in 1Q2021. Furthermore, we include an exogenous transfer path that considers additional fiscal measures (Kindergeld, short-time work payments, grants and other transfers) that affect the consumption and savings decision. That is the experiment that best matches real development. We compare the results with the same simulated series without the VAT reduction. Furthermore, we run further experiments to analyze the channels of the VAT effect without the transfer scheme, without a lockdown, a VAT reduction only for non-durables, a VAT reduction only for only durables, with active monetary policy instead of the ZLB and with a second surprise VAT reduction in 2021.

\subsection{How Effective is the VAT Reduction during the Lockdown in Germany?}

Figure 3 depicts the development of GDP, consumption, non-durable goods consumption, durable goods consumption, private investments, the debt-to-GDP ratio, CPI inflation, nominal interest rate and the ex-ante real interest rate. ${ }^{18}$ All variables are represented in real terms and in the form of target gaps, that is deviation from max-min trend range (blue area).

We simulate unexpected lockdown shocks in 2Q2020 19 and in 4Q2020:1Q2021 as a benchmark without the VAT reduction (red line). In addition, we include forced savings shocks in the lockdown periods to match the observed savings rate. Finally, we run a simulation where we include an unexpected VAT reduction in 3Q2020:4Q2020 (dashed blue line) into this setup. ${ }^{20}$

As can be seen, this simulated series with all three shocks traces back the empirically observed paths quite well. We can see that the VAT reduction in the short run mainly works through durable and non-durable goods consumption. It strongly increases durable goods consumption in 3Q2020 and 4Q2020 because the VAT change has reduced the rental price for durable goods (durable goods effect). The VAT reduction propagates its largest effect in the fourth quarter because here, in addition to higher demand for consumer durable goods, households

\footnotetext{
${ }^{17}$ Note that the VAT tax rate for most consumption goods is $19 \%$. Some consumption goods, i.e. food, necessities, have reduced tax rates of $7 \%$.

${ }^{18}$ See Subsection B.1 in the Appendix for detailed data descriptions.

${ }^{19}$ More precisely, the lockdown had already started in the last week of the first quarter. The two lockdowns have many elements in common, but they are not identical. Using mobility data, a recent study by the Rossbach von Storch Institute shows that on average, mobility and visits in retail stores were affected about $75 \%$ as much in the second lockdown compared to the first, when measured as average over the second and fourth quarter. Temporary close downs in industry were stronger in the first lockdown because the drop in GDP and components in the first quarter is mainly related to the reduction in trade. To concentrate on the pure lockdown effects, we decided to start our analysis in 2Q2020.

${ }^{20}$ The German government has announced the VAT reduction in mid June 2020 . Thus, the last 2 weeks of $2 Q 2020$ consumption could also be affected by announcement effects that would shift consumption from 2Q2020 into 3Q2020.
} 

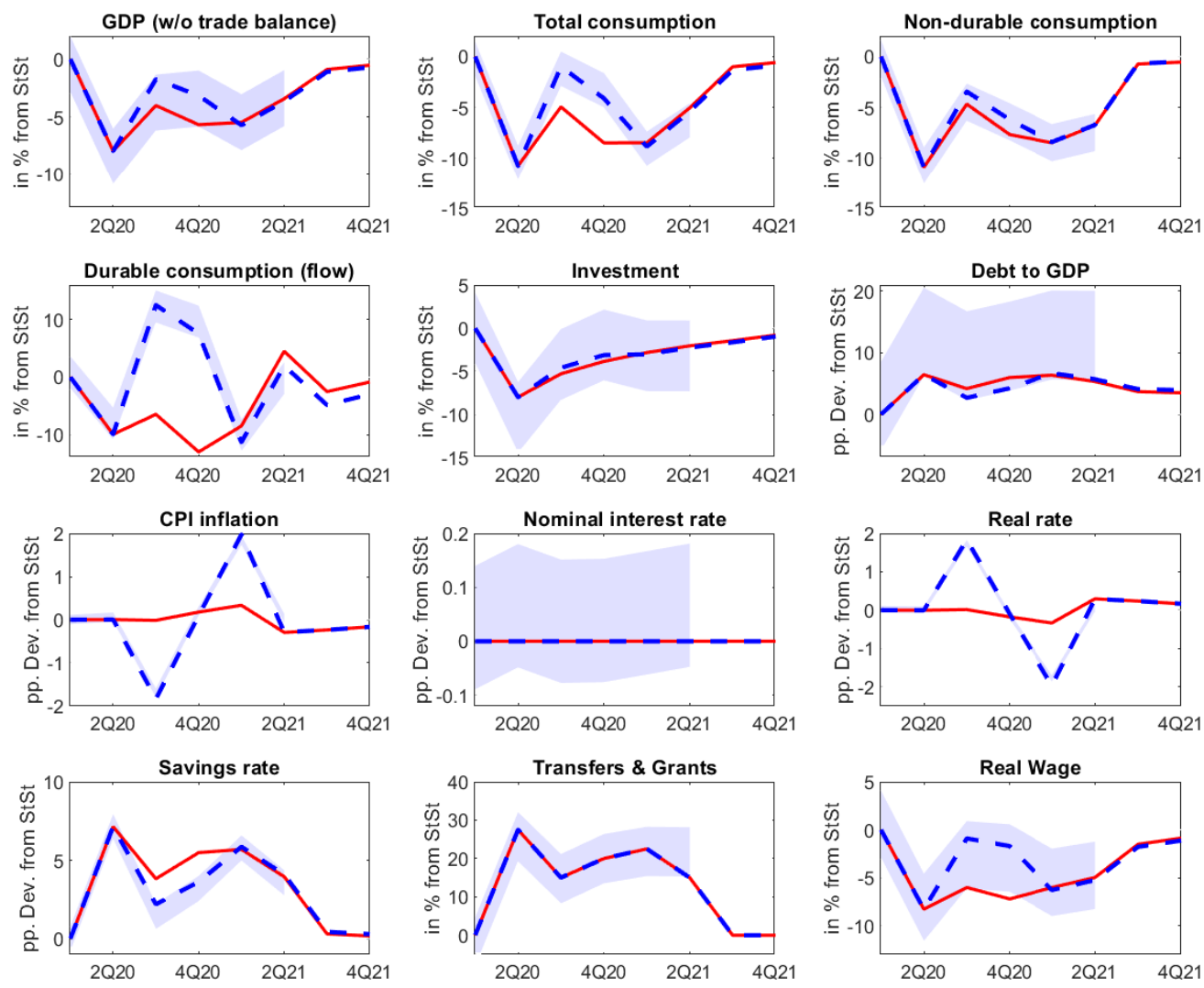

max-min

- without VAT reduction - - with VAT reduction

Figure 3: Unexpected lockdown shocks in 2Q2020 and 4Q2020-2Q2021 with (blue) and without (red) an unexpected VAT rate reduction of $3 \mathrm{pp}(3 \mathrm{Q}-4 \mathrm{Q} 2020)$

also increase non-durable goods consumption in expectation of future price increases (arbitrage effect). Altogether the VAT reduction raises real GDP initially by roughly $1 \%$ compared to the baseline simulation with a constant VAT rate in 2020. However, the cumulative medium-term effect on GDP is significantly smaller. Total consumption increases by $1.5 \%$ on impact. Private investment stays almost constant in the short and medium run, mainly because there is no accommodating monetary policy response. ${ }^{21}$

In addition to analyzing the real economic effects, it is worth examining the CPI inflation rate, public finance and the debt-to-GDP ratio. In the case of the CPI inflation rate, we can see that the sharp drop in 2 Q2020 is to some extent attributed to the demand disruptions that are a consequence of the lockdown shock. The main part of the drop can be attributed to the VAT reduction. In terms of public finance, our model predicts that the debt-to-GDP ratio increases by $7 \%$ in the first year. Within the simulation, we consider financial aid for firms and households as transfer shock, but we do not consider additional government spending from the stimulus

\footnotetext{
${ }^{21}$ Furthermore, we do not consider that firms that do not pass through the VAT rate reduction increase their level of liquidity and their equity capital. This could lead to increasing investments in the future if those firms finance future investment via equity and liquid funds.
} 
package and additional credit and shareholdings. Due to its relative effectiveness, the VAT change reduces the debt-to-GDP ratio by 0.7 percentage points in 2020, and it slightly increases over the medium term.
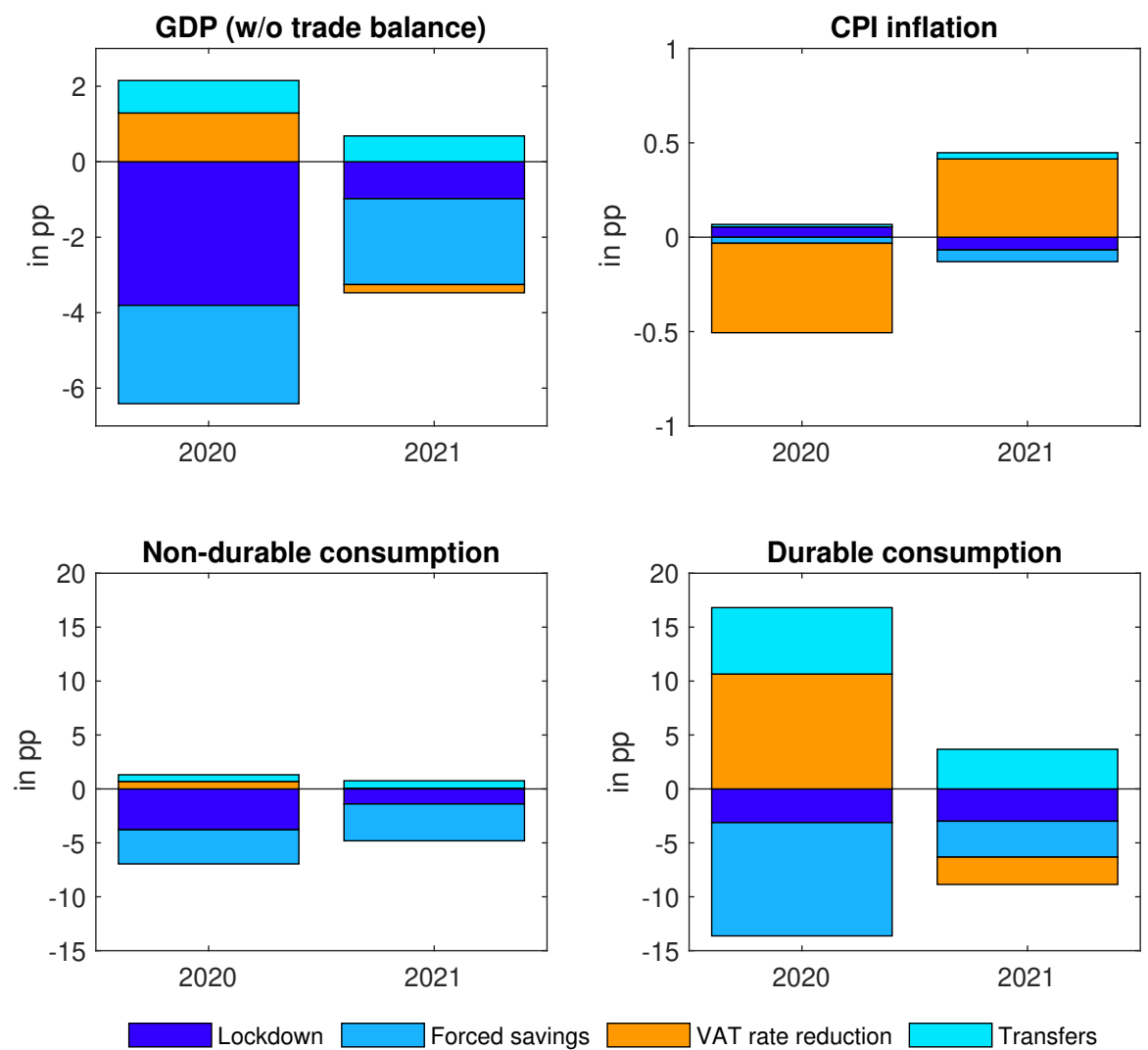

Figure 4: Decomposition of the VAT Effect in Germany

We use our model to disentangle the contributions of the different shocks in 2020 and 2021, lockdown, transfer, forced savings and the VAT policy. Figure 4 depicts the contributions of these shocks to GDP (without the trade balance), CPI inflation, and non-durable and durable goods consumption in relation to their steady-state values. GDP has reduced by more than $4 \%$ of its steady-state value due to the lockdown. Forced savings and other uncertainty-related additional savings have contributed to the GDP reduction by 2 percentage points. Thus, in total, supply- and demand-related shocks of the pandemic have reduced GDP by $6 \%$ of its steady state. The government transfer and the VAT policy have dampened the reduction by $2 \%$, where each stabilization policy contributed $1 \mathrm{pp}$.

Therefore, in absolute terms, VAT reduction has increased GDP by 32 bn euros in 2020. The VAT reduction does not stabilize affected sectors during the lockdown, because they close down production, and thus, consumption is almost zero. In terms of the lockdown shock, it stabilizes production in the non-affected sector that also experiences losses due to spillover effects. The VAT-related price reduction mainly counteracts uncertainty- and lockdown-related consumption reservation, and thus, the forced saving shock in 2020. In 2021, the contribution of the lockdown shock to GDP development has diminished, mainly because the lockdowns in 2021 were less 
restrictive in Germany. The forced savings effect is similar to that of 2020. The stabilization due to transfer payments and the force savings shock is similar because the absolute value of transfers stays constant (See Table 3 in the Appendix.). However, in 2021, the VAT readjustment reduces GDP due to price increases and missing durable goods consumption that is shifted towards 2020 .

The price effects can be measured using the CPI inflation rate. According to our baseline calibration the VAT reduction has reduced the annual CPI inflation by $0.5 \%$ of steady-state inflation in 2020 . This effect translates almost one to one to the increase of consumer price inflation in $2021 .{ }^{22}$

By comparing the effect on different consumption categories separately, we can see that our model also replicates our observation that both consumption categories decreased due to the lockdown and also due to forced savings. The major impact of the VAT policy translates to the economy via a more than $10 \%$ increase in durable consumption goods in the year of impact. In combination with the transfers, the demand for durable goods was stabilized. Both have minor effects on the consumption of non-durable goods. The VAT policy affects durable goods negatively, in 2021 because they were shifted forward to a much larger extent.

\subsection{Temporary VAT Multiplier During the Lockdown}

Finally, we present a robust validation of temporary VAT multipliers and effects based on the different model simulations. The VAT multiplier is defined as cumulative change of GDP divided by the cumulative change of VAT revenues $\frac{\sum_{t=0}^{k} \Delta y_{t+k}}{\sum_{t=0}^{k} \Delta T_{t+k}^{V A T}}$ in reaction to a $3 \mathrm{pp}$ reduction of the VAT rate. Table 1 summarizes the results. In general, we distinguish between the impact effect in year $2020(k=2$, second column), the first year impact ( $k=4$, third column) and the cumulative 5 -year (medium term) multipliers $(k=20$, fourth column).

Table 1: VAT Multiplier: Lockdown vs. No Lockdown

\begin{tabular}{lccc}
\hline Frequency & 3Q \& 4Q & after 1 year & after 5 years \\
\hline \multicolumn{4}{c}{ No Lockdown } \\
\hline w/o durable goods, no ZLB & 0.68 & 0.55 & 0.17 \\
with durable goods, no ZLB & 2.11 & 1.60 & 0.65 \\
with durable goods, ZLB & 1.92 & 1.65 & 1.01 \\
\hline \multicolumn{4}{c}{ Lockdown - Baseline } \\
\hline Lockdown, ZLB & 1.77 & 1.48 & 0.82 \\
\hline \hline
\end{tabular}

Note: We simulate an unexpected VAT rate reduction of $-3 \mathrm{pp}$ for two periods. The VAT multiplier is defined as the cumulative change of GDP divided by the cumulative change of VAT revenues.

In the first part of the table, we can see the multipliers with and without durable goods, without considering the lockdown shock and with an active monetary policy following a Taylor rule. Note that for simulations without the durable goods effect we confirm the literature result, of cumulative VAT multipliers between 0.2 and $0.8 .^{23}$ In

\footnotetext{
${ }^{22}$ Note that the CPI inflation in 2021 is $3.1 \%$. Assuming a 10 -year trend CPI inflation of $1.8 \%$ for Germany, the VAT readjustment leads to a CPI inflation rate of $2.3 \%$. The introduction of carbon pricing in Germany ( 25 p €er barrel carbon dioxide) and the convergence of international oil prices ( $68 \%$ annual increase, $5 \%$ share in the consumption basket) can explain the difference in the observed CPI inflation rate in 2021.

${ }^{23}$ See, e.g., Sims and Wolff (2018), Claus (2013).
} 
Table 2: VAT Multiplier: Counterfactuals

\begin{tabular}{|c|c|c|c|}
\hline Frequency & $3 Q \& 4 Q$ & after 1 year & after 5 years \\
\hline \multicolumn{4}{|c|}{ Lockdown - Counterfactuals } \\
\hline Lockdown, ZLB, no Kinderbonus & 1.67 & 1.35 & 0.59 \\
\hline Lockdown, No ZLB & 2.36 & 2.24 & 1.67 \\
\hline Lockdown, ZLB, full pass-through & 3.35 & 2.58 & 0.99 \\
\hline Lockdown, ZLB, second VAT shock & 1.38 & 0.73 & -0.49 \\
\hline \multicolumn{4}{|c|}{ Lockdown - Baseline } \\
\hline Lockdown, ZLB & 1.77 & 1.48 & 0.82 \\
\hline
\end{tabular}

Note: We simulate an unexpected VAT rate reduction of $-3 \mathrm{pp}$ for twi periods. The VAT multiplier is defined as a cumulative change of GDP divided by the cumulative change of VAT revenues.

our case, without durable effect, we estimate a cumulative VAT multiplier of 0.68 in the two quarters of impact, 0.55 after one year and almost 0.2 over the medium term. If we include durable goods, the effectiveness of a temporary VAT reduction increases substantially to more than 2.11 euros in the two quarters of impact, 1.6 after the first year and 0.65 over the medium term. The effect is less pronounced if we consider a ZLB because the central bank does not accommodate the VAT policy via an interest rate cut due to lower inflation. In this case, the VAT multiplier in the two quarters of impact is above $1.92 .^{24}$

However, we must consider the recent pandemic lockdown in Germany. The lockdown restricts consumption, especially for LC households. Therefore, consumption demand cannot be extended as planned. In addition, forced savings and an alternative government transfer that started and ended in the same periods ('Kinderbonus') should be included in our model simulation to evaluate the effect of the VAT reduction. In the Lockdown situation with forced savings and all transfers, the VAT multiplier reduces to 1.77 in the two quarters of impact, 1.48 after one year and 0.82 in the medium term.

Overall, the VAT rate reduction is an effective instrument to stabilize consumption, especially durable goods consumption, in the short term in the case of the lockdown shock. The cumulative GDP effect diminishes over the medium term to values significantly below one for all scenarios because front loading of durable goods consumption leads to lower consumption in the following periods. This effect leads to fiscal costs in the medium term.

Finally, we run further counterfactual simulations. The results are summarized in Table 2: Without the additional 'Kinderbonus' transfer that was also part of the German stimulus package, the VAT multiplier becomes slightly less effective, which indicates that both measures are complementary. Without the ZLB and with an active monetary policy following the Taylor rule, the VAT effect on GDP in the lockdown would be higher, as expected from the 'No Lockdown' scenario. With a full pass-through, the VAT effect is much more effective and above 2 after 1 year. However, governments will find it difficult to motivate firms to fully adjust their prices. In a final counterfactual scenario, we also simulate a second surprise VAT reduction of $0.3 \mathrm{pp}$ in the first two quarters

\footnotetext{
${ }^{24}$ Note, if we use a different definition of the multiplier, where only the initial shortfall of VAT revenues is considered, the multiplier is smaller in magnitude but still above 1 in most cases. For example, in the "No Lockdown" scenario with ZLB, the multiplier is 1.5 after 2 quarters, 1.3 after one year and 0.88 after 5 years. Thus 0.4 euros of the VAT multiplier can be associated with second-round effects where increasing consumption demands dampens the initial shortfall of tax revenues.
} 
of 2021. Comparing the multiplier of the second VAT policy shows that this policy is much less effective, mainly because durable goods demand has a long recreation time that lasts until the additional durable goods stock is depreciated. Therefore, the government should keep in mind that while one unexpected temporary VAT reduction can be helpful, unexpected extensions or additional subsequent VAT reductions will be much less effective.

\section{Conclusion}

In the aftermath of the first lockdown in June 2020, the German government decided to stimulate the economy via a temporary VAT rate reduction. After its announcement, a lively debate has began in Germany about the advantages and disadvantages of this policy measure and its effectiveness during the pandemic.

In this paper, we investigate the macroeconomic effects of the temporary VAT change in the specific case of Germany during the partial lockdown. Therefore, we set up a DSGE model for Germany under the lockdown and with monetary policy operating at the ZLB. We extend our model with durable goods and imperfect VAT pass-through (Clemens and Roeger (2022)) further by specific features such as a sectoral structure and a lockdown shock that make it especially suitable for analyzing the channels at work and applying the model to the specific situation of Germany. We match the model to German data and show the impact of the lockdown shocks and the VAT shock on relevant macroeconomic aggregates in 2Q2020:2Q2021. Our simulation considers that lockdowns and the VAT reduction are unanticipated. Furthermore, we also consider forced savings and government transfers (short-time work payments, transfers to firms and households) as driving forces of the recovery process.

We simulate the model with the specific lockdown situation with and without the VAT reduction. The difference between both scenarios yield the total effect of the VAT reduction. We find that the lockdown situation reduces the VAT effectiveness because it restricts consumption temporarily. In particular, we find that the VAT reduction has led to a strong increase in the demand for consumer durable goods, which is the main transmission channel predicted by the model. Overall, for the specific situation in Germany 2020, we find a VAT short-term multiplier of 1.8 per euro or, in total, 32 bn euros. Over the medium term, it reduces to values significantly below 1. Thus, the temporary VAT reduction is an effective instrument in the short-term but not efficient in terms of the medium-term budget sustainability.

Finally, we run additional counterfactual scenarios to analyze whether other policies can support the VAT reduction. We show that simultaneous transfers to poorer families, as was done by the German government with the "Kinderbonus", support the VAT policy. Although difficult to implement, a policy that motivates firms to fully pass through the VAT reduction to sales prices strongly increases the GDP effect of the VAT reduction. Easier in practice but similarly effective would be a VAT reduction only for durable goods. But in a lockdown situation, it might be difficult to argue for a VAT reduction that appears to only benefit durable goods producers . Finally, we find that subsequent temporary surprise VAT reductions are much less effective, especially for durable goods. 


\section{Appendix}

\section{A Figures}
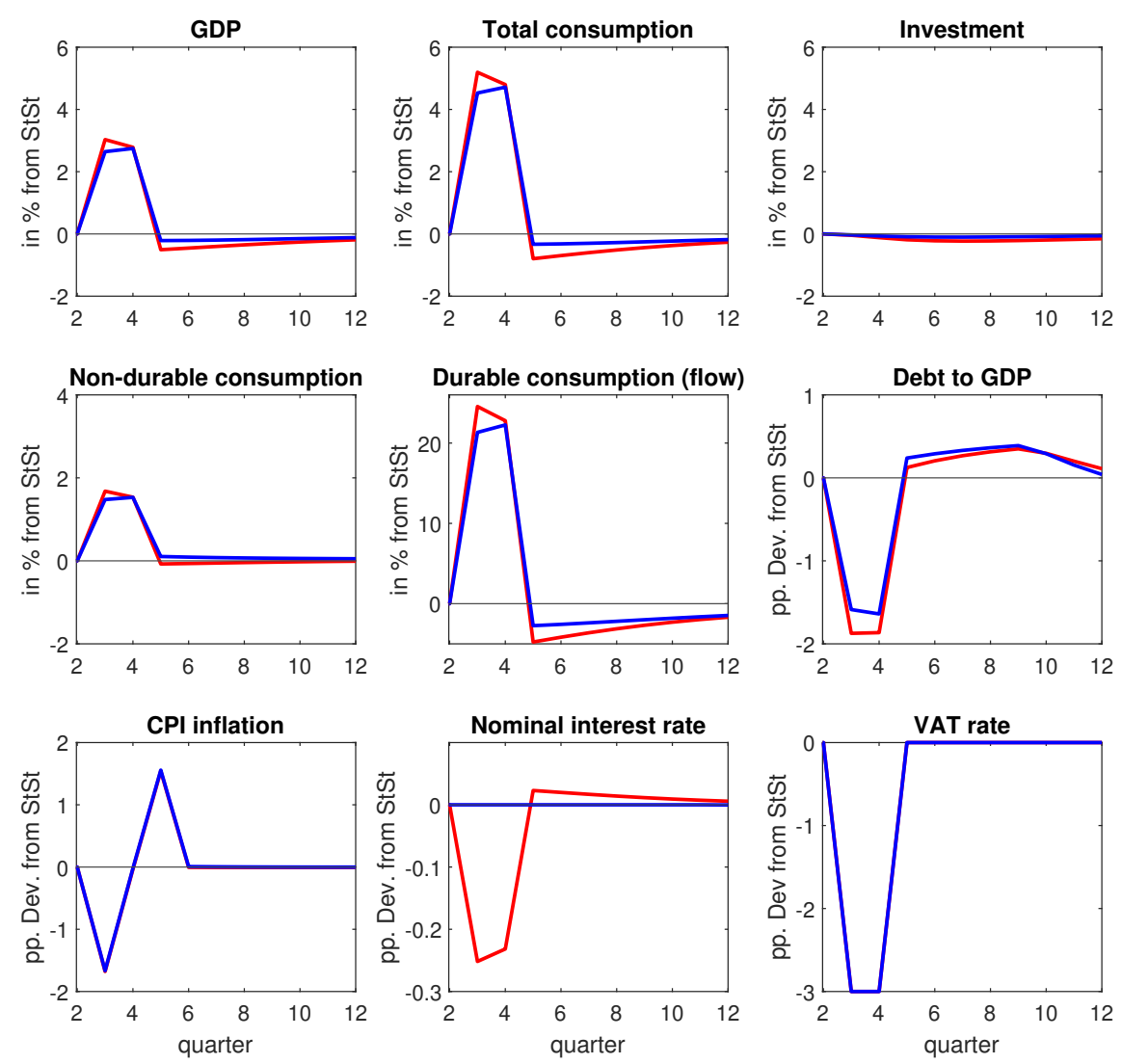

VAT rate shock (Taylor Rule) — VAT rate shock (ZLB)

Figure 5: VAT rate shock, $-3 \mathrm{pp}$ for 2 periods

\section{B Tables}

Table 3: Transfers and grants, Germany 2Q2021-2Q2021

\begin{tabular}{lccccc}
\hline in bn Euro & $\mathbf{2 Q 2 0}$ & $\mathbf{3 Q 2 0}$ & $\mathbf{4 Q 2 0}$ & $\mathbf{1 Q 2 1}$ & $\mathbf{2 Q 2 1}$ \\
\hline \hline Firm grants (Emergency aid programs) & 13.5 & 5.2 & 8.2 & 11 & 11 \\
Short-time work payments & 6 & 1.8 & 2 & 4 & 3 \\
Children transfer payment (Kinderbonus) & & 2.2 & 2.2 & 0.6 & 0.6 \\
Total & 19.5 & 9.2 & 12.4 & 15.6 & 14.6 \\
\hline$\%$ from real GDP & 0.5 & 0.26 & 0.36 & 0.45 & 0.42 \\
\hline
\end{tabular}

Source: German Federal Statistics Office: National Account Statistics (2021), Dashboard Germany (2021) 
Table 4: Matching Macro and Fiscal Policy

\begin{tabular}{|c|c|c|c|}
\hline & Notation & Value & DEU \\
\hline \multicolumn{4}{|l|}{ Macroeconomy } \\
\hline Private consumption & $\frac{\bar{C}}{\bar{Y}}$ & $\%$ of GDP & 0.56 \\
\hline Durable \& semi-durable consumption & $\frac{\overline{I D}}{\bar{Y}}$ & $\%$ of GDP & 0.2 \\
\hline Private investment & $\frac{\bar{I}}{\bar{Y}}$ & $\%$ of GDP & 0.18 \\
\hline Net exports & $\frac{\frac{1}{N X}}{\bar{Y}}$ & $\%$ of GDP & 0.05 \\
\hline Wage income per GDP & $\frac{\bar{w} \bar{L}}{\bar{Y}}$ & $\%$ of GDP & 0.53 \\
\hline Capital output ratio & $\frac{\bar{k}}{\bar{y}}$ & $\%$ of GDP & 2.99 \\
\hline \multicolumn{4}{|l|}{ Expenditures per GDP } \\
\hline Public expenditures & $\frac{\bar{G}}{\bar{\gamma}}$ & $\%$ of GDP & 0.2 \\
\hline Interest rate payments & $\frac{\frac{I G}{\overline{I G}}}{\bar{\gamma}}$ & $\%$ of GDP & 0.02 \\
\hline \multicolumn{4}{|l|}{ Fiscal balance } \\
\hline Transfers $/ \operatorname{Tax}^{1}$ & $\frac{\bar{T}}{\underline{Y}}$ & $\%$ of GDP & 0.33 \\
\hline Debt to GDP & $\frac{\bar{b}}{\bar{Y}}$ & $\%$ of GDP & 0.60 \\
\hline
\end{tabular}

Source: AMECO, OECD National Accounts, OECD Tax Database. ${ }^{1}$ Empirically, this component is defined as other expenditures (mainly transfers) minus other revenues (mainly other taxes and social contributions). In the model this variable is an indicator of fiscal surpluses/deficits and thus it measures the fiscal space.

\section{B.1 Data description}

Gross Domestic Product: Federal Statistic Office, National Accounts Statistics, Series 18 1.2, Gross Domestic Product, price-adjusted (chain-linked volume), seasonally-adjusted, 1Q1991-2Q2021.

Consumption: Federal Statistic Office, National Accounts Statistics, Series 18 1.2, Private Consumption, priceadjusted (chain-linked volume), seasonally-adjusted, 1Q1991-2Q2021.

Expandable consumption: Federal Statistic Office, National Accounts Statistics, Series 18 1.2: Private Consumption and Disposable Income, Expandable Consumption, price-adjusted (chain-linked volume), seasonally-adjusted, 1Q1991-2Q2021.

Short-lived consumption: Federal Statistic Office, National Accounts Statistics, Series 18 1.2: Short-lived Consumption and Disposable Income, Expandable Consumption, price-adjusted (chain-linked volume), seasonallyadjusted, 1Q1991-2Q2021.

Long-lived consumption: Federal Statistic Office, National Accounts Statistics, Series 18 1.2: Private Consumption and Disposable Income, Long-lived Consumption, price-adjusted (chain-linked volume), seasonally-adjusted, 1Q1991-2Q2021.

Services: Federal Statistic Office, National Accounts Statistics, Series 18 1.2: Private Consumption and Disposable Income, Services, price-adjusted (chain-linked volume), seasonally-adjusted, 1Q1991-2Q2021.

Non-durable consumption: Expandable consumption + Services.

Durable consumption: Short-lived consumption + long-lived consumption. 
Private investments: Federal Statistic Office, National Accounts Statistics, Series 18 1.2, Non-governmental investments, price-adjusted (chain-linked volume), seasonally-adjusted, 1Q1991-2Q2021.

CPI inflation rate: Federal Statistic Office, National Accounts Statistics, Series 18 1.2, Private consumption price deflator, price-adjusted (chain-linked volume), seasonally-adjusted, 1Q1991-2Q2021.

Nominal interest rate: FRED, Immediate Rates: Less than 24 Hours: Call Money/Interbank Rate for Germany, 1Q1991-2Q2021.

Ex-ante real interest rate: Nominal interest rate - CPI inflation rate.

Table 5: Parameter Values

\begin{tabular}{|c|c|c|c|}
\hline Name & Parameter & Value & Target \\
\hline \multicolumn{4}{|l|}{ Structural parameter } \\
\hline Labor prod. elasticity & $\alpha^{L}$ & 0.675 & $\frac{\bar{w} \bar{L}}{\bar{\gamma}}$ \\
\hline Capital prod. elasticity & $\alpha^{K}$ & 0.325 & $1-\alpha^{L}$ \\
\hline Time preference & $\beta$ & 0.996 & annualized $r=1.6 \%$ \\
\hline Depreciation rate (Investment) & $\delta$ & 0.014 & $\frac{K}{Y}$ \\
\hline Labour supply elasticity & $\rho$ & 0.5 & See text \\
\hline Price markup & $\mu^{P}$ & 0.1 & $10 \%$ price markup \\
\hline Wage markup & $\mu^{W}$ & 0.1 & $10 \%$ wage markup \\
\hline Share of LC households & $s^{L}$ & 0.28 & Direct match \\
\hline Government expenditures per GDP & $g^{Y}$ & 0.2 & See Table 4 \\
\hline \multicolumn{4}{|l|}{ Adjustment costs } \\
\hline Price adj. costs (A sector) & $\gamma^{P, 1}$ & 20 & Burgert et al. (2020) \\
\hline Price adj. costs (NA sector) & $\gamma^{P, 2}$ & 20 & Burgert et al. (2020) \\
\hline VAT pass-through & $\gamma^{V A T}$ & 0.4 & See Subsection 3.3 \\
\hline Wage adj. costs (A sector) & $\gamma^{W, 1}$ & 120 & Burgert et al. (2020) \\
\hline Wage adj. costs (NA sector) & $\gamma^{W, 2}$ & 120 & Burgert et al. (2020) \\
\hline Investment adj. costs & $\gamma^{I}$ & 75 & Burgert et al. (2020) \\
\hline Capital adj. costs & $\gamma^{K}$ & 20 & Burgert et al. (2020) \\
\hline Durable adj. costs & $\gamma^{D}$ & 3 & See text \\
\hline Retail price adj. costs & $\gamma^{P, \text { ret }}$ & 20 & Burgert et al. (2020) \\
\hline \multicolumn{4}{|l|}{ Lockdown sector parameter } \\
\hline Production share A sector (durable goods) & $\psi^{D, 1}$ & 0.01 & Lockdown match \\
\hline Production share A sector (non-durable goods) & $\psi^{N, 1}$ & 0.06 & Lockdown match \\
\hline SE between sectors & $\sigma^{D}=\sigma^{D}$ & 0.7 & See text \\
\hline
\end{tabular}


Table 5 - Continued

\begin{tabular}{lccc}
\hline Name & Parameter & Value & Target \\
\hline \hline Durable, Non-Durable goods and Investments & & & \\
\hline Depreciation rate (durable goods) & $\delta^{D}$ & 0.025 & See text \\
Durable + semi-durable consumption share & $\psi^{D}$ & 0.2 & Direct Match \\
SE between durable and non-durable goods & $\sigma^{N D}$ & 0.75 & See text \\
\hline Fiscal policy & & & \\
\hline Value added tax rate & $\bar{\tau}^{V A T}$ & 0.175 & See Table 4 \\
Public debt to GDP & $\bar{b} / \bar{y}$ & 2.4 & $60 \%$ Debt-to-GDP ratio \\
Fiscal rule: Stance of public debt level & $\phi_{b}$ & 0.625 & See text \\
Fiscal rule: Stance of new debt & $\phi_{d b}$ & 0.0625 & See text \\
Tax/Transfers per GDP & $T$ & 0.33 & See Table 4 \\
\hline Monetary policy & & & See text \\
\hline Interest smoothing & $\phi^{i}$ & 0.9 & See text \\
Inflation target & $\phi^{\pi}$ & 1.5 & See text \\
Output gap target & $\phi^{y}$ & 0.0 &
\end{tabular}




\section{Derivation of the Sales Price Reaction to a Change in VAT}

Starting from the price setting equation of the retail firm

$$
P_{t}^{r e t}=\left(1+\mu_{t}^{r e t}\right)+\gamma^{P, r e t}\left(\beta\left(E_{t} \pi_{t+1}^{r e t}+\frac{\gamma^{V A T}}{1+\tau^{V A T}}, E_{t} \Delta \tau_{t+1}^{V A T}\right)-\left(\pi_{t}^{r e t}+\frac{\gamma^{V A T}}{1+\tau^{V A T}} \Delta \tau_{t}^{V A T}\right)\right)
$$

In order to show how the change in VAT translates into consumer price we can simplify the retail price inflation by taking the logarithm and rewrite it in price level:

$$
\begin{aligned}
& p_{t}^{r e t}-p_{t-1}^{r e t}=\mu_{t}^{r e t}+\beta\left(E_{t} p_{t+1}^{r e t}-p_{t}^{r e t}\right)+\frac{\beta \gamma^{V A T}}{1+\tau^{V A T}} E_{t} \Delta \tau_{t+1}^{V A T}-\frac{\gamma^{V A T}}{1+\tau^{V A T}} \Delta \tau_{t}^{V A T}+\frac{1}{\gamma^{r e t}} p_{t}^{r e t} \\
& E_{t} p_{t+1}^{r e t}-\left(\frac{1+\beta+\frac{1}{\gamma^{r e t}}}{\beta}\right) p_{t}^{r e t}+\frac{1}{\beta} p_{t-1}^{r e t}=-\frac{\gamma^{V A T}}{1+\tau^{V A T}}\left(E_{t} \Delta \tau_{t+1}^{V A T}-\frac{1}{\beta} \Delta \tau_{t}^{V A T}\right)-\frac{1}{\gamma^{P, r e t}} \mu_{t}^{r e t}
\end{aligned}
$$

By factorizing with the Lag operator $L$, we can rewrite the 2 nd order difference equation as

$$
\left(1-\lambda_{1} L\right)\left(1-\lambda_{2} L\right) p_{t}^{r e t}=-\frac{\gamma^{V A T}}{1+\tau^{V A T}}\left(\Delta \tau_{t}^{V A T}-\frac{1}{\beta} \Delta \tau_{t-1}^{V A T}\right)-\frac{1}{\gamma^{P, r e t}} \mu_{t}^{r e t}
$$

with the characteristic roots $\lambda_{1} \leq 1$ and $\lambda_{2}>1$. The roots can be calculated by solving the non linear equations

$$
\begin{array}{r}
\left(\lambda_{1}+\lambda_{2}\right)\left(\frac{1+\beta+\frac{1}{\gamma^{P, r e t}}}{\beta}\right)-\frac{1}{\beta}=0 \\
\lambda_{1} \lambda_{2}=\frac{1}{\beta}
\end{array}
$$

This yields a mixed quadratic equation, which can be solved according to

$$
\lambda_{1,2}=\frac{1}{2} \frac{1+\beta+\frac{1}{\gamma^{P, r e t}}}{\beta} \pm \sqrt{-\frac{1}{2}\left(\frac{1+\beta+\frac{1}{\gamma^{P, r e t}}}{\beta}\right)^{2}-\frac{1}{\beta}}
$$

The root larger than one can be solved forward using the following transformation:

$$
\frac{1}{1-\lambda_{2} L}=\frac{\frac{1}{\lambda_{2}} L^{-1}}{\frac{1}{\lambda_{2}} L^{-1}\left(1-\lambda_{2} L\right)}=-\frac{\frac{1}{\lambda_{2}} L^{-1}}{\left(1-\frac{1}{\lambda_{2}} L^{-1}\right)}
$$

Inserting it back to the consumer price equation

$$
\left(1-\lambda_{1} L\right)\left(1-\lambda_{2} L\right) p_{t}^{r e t}=\frac{\frac{1}{\lambda_{2}}}{\left(1-\frac{1}{\lambda_{2}} L^{-1}\right)}\left(\frac{\gamma^{V A T}}{1+\tau^{V A T}}\left(E_{t} \Delta \tau_{t+1}^{V A T}-\frac{1}{\beta} \Delta \tau_{t}^{V A T}\right)+\frac{1}{\gamma^{P, r e t}} \mu_{t}^{r e t}\right)
$$

and iterating forward yields:

$$
p_{t}^{r e t}=\lambda_{1} p_{t-1}^{r e t}+\frac{1}{\lambda_{2}} \sum_{j=0}^{\infty}\left(\left(\frac{1}{\lambda_{2}}\right)^{j} \frac{\gamma^{V A T}}{1+\tau^{V A T}}\left(E_{t} \Delta \tau_{t+1+j}^{V A T}-\frac{1}{\beta} \Delta \tau_{t+j}^{V A T}\right)+\frac{1}{\gamma^{P, r e t}} \mu_{t+j}^{r e t}\right)
$$


In a next step we establish the relationship between retail and consumer prices $p_{t}^{C}=p_{t}^{\text {ret }}+\log \left(1+\tau_{t}^{V A T}\right)=$ $p_{t}^{r e t}+\tau_{t}^{V A T}$ and consumer price inflation $\pi_{t}^{C}=p_{t}^{\text {ret }}-p_{t-1}^{\text {ret }}+\Delta \tau_{t}^{V A T}$

$$
\pi_{t}^{C}=\left(\lambda_{1}-1\right) p_{t-1}^{r e t}+\Delta \tau_{t}^{V A T}+\frac{1}{\lambda_{2}} \sum_{j=0}^{\infty}\left(\frac{1}{\lambda_{2}}\right)^{j}\left(\frac{\gamma^{V A T}}{1+\tau^{V A T}}\left(E_{t} \Delta \tau_{t+1+j}^{V A T}-\frac{1}{\beta} \Delta \tau_{t+j}^{V A T}\right)+\frac{1}{\gamma^{P, r e t}} \mu_{t+j}^{r e t}\right)
$$




\section{Model equations}

\section{D.1 Sectoral Firm Structure}

Sector $j=1,2$. Sector 1 is the affected Lockdown sector, Sector 2 is the non-affected sector.

(1) Sectoral production function

$$
Y_{t}^{j}=A^{j}\left(K_{t}^{j}\right)^{\alpha^{K}}\left(L_{t}^{j}\right)^{\alpha^{L}}
$$

(2) Sectoral price setting

$$
\frac{w^{r, j} L_{t}{ }^{j}}{\alpha^{L} Y^{j}{ }_{t}}=\left(1-\mu^{P}-\gamma^{P, j} \beta\left(E_{t} \pi_{t+1}^{Y, j}+\gamma^{V A T} E_{t} \Delta \tau_{t+1}^{V A T}\right)+\gamma^{P, j}\left(\pi_{t}^{Y, j}+\gamma^{V A T} \Delta \tau_{t}^{V A T}\right)\right)
$$

(3) Sectoral investment price

$$
\begin{aligned}
& Q_{t}^{j}=\frac{\beta U^{\prime}\left(E_{t} C_{t+1}^{R}\right) E_{t} Q_{t+1}^{j}}{U^{\prime}\left(C_{t}^{R}\right)\left(1+E_{t} \pi_{t+1}^{C, R}\right)} \\
& \quad\left(\alpha \frac{Y_{t}^{j}}{K_{t}^{j}}\left(1-\left(\mu^{P}+\gamma^{P, j}\left(\beta\left(\theta^{P} E_{t} \pi_{t+1}^{Y, j}+\left(1-\theta^{P}\right) \pi_{t-1}^{Y, j}\right)-\left(1+\beta \gamma^{V A T}\right) \pi_{t}^{Y, j}+\gamma^{V A T} \pi_{t-1}^{Y, j}\right)\right)\right)+1-\delta\right)
\end{aligned}
$$

(4) Sectoral investment demand

$$
Q_{t}^{j}=1+\gamma^{K}\left(\frac{I_{t}^{j}}{K_{t-1}^{j}}-\frac{I^{j}}{K^{j}}\right)+\gamma^{I}\left(I_{t}^{j}-I_{t-1}^{j}\right)-\gamma^{I} \beta \frac{U^{\prime}\left(E_{t} C_{t+1}^{R}\right)}{U^{\prime}\left(C_{t}^{R}\right)}\left(E_{t} I_{t+1}^{j}-I_{t}^{j}\right)
$$

(5) Sectoral capital accumulation

$$
I_{t}^{j}=K_{t}^{j}-(1-\delta) K_{t-1}^{j}
$$

(6) Retail price setting

$$
P_{t}^{r e t}=1+\mu^{P, r e t}+\gamma^{P, r e t}\left(\beta\left(E_{t} \pi_{t+1}^{r e t}+\gamma^{V A T} E_{t} \Delta \tau_{t+1}^{V A T}\right)-\left(\pi_{t}^{r e t}+\gamma^{V A T} \Delta \tau_{t}^{V A T}\right)\right)
$$

(7) Retail price inflation

$$
\pi_{t}^{r e t}-\pi_{t}^{\gamma}=\frac{P_{t}^{r e t}}{P_{t-1}^{r e t}}-1
$$

(8) Sectoral labour supply

$$
U^{\prime}\left(L_{t}^{j}\right)=-\omega^{j}\left(L_{t}^{j}\right)^{\rho}
$$

(9) Sectoral wage setting

$$
w_{t}^{C, j}=\frac{\left(-U^{\prime}\left(L_{t}^{j}\right)\right)\left(1+\mu^{W}+\gamma^{W, j}\left(\beta E_{t} \pi_{t+1}^{W, j}-\pi_{t}^{W, j}\right)\right)}{\left(1-\bar{\tau}^{W}\right)\left(s^{L} U^{\prime}\left(C_{t}^{L}\right)+U^{\prime}\left(C_{t}^{R}\right)\left(1-s^{L}\right)\right)}
$$

(10) Sectoral real wage (CPI)

$$
w_{t}^{C, j}=\frac{w_{t}^{r, j} P_{t}^{Y, j}}{s^{L} P_{t}^{C, L}+\left(1-s^{L}\right) P_{t}^{C, R}}
$$


(11) Sectoral real wage (PPI)

$$
w_{t}^{r, j}=\frac{w_{t-1}^{r, j}\left(1+\pi_{t}^{W, j}\right)}{1+\pi_{t}^{Y, j}}
$$

(12) Relative prices (good 2 is the numeraire)

$$
\frac{1+\pi_{t}^{Y, 1}}{1+\pi_{t}^{Y, 2}}=\frac{P_{t}^{Y, 1}}{P_{t-1}^{Y, 1}}
$$

(13) Resource constraint (sector 1: affected sector)

$$
Y_{t}^{1}=s^{L} N D_{t}^{L, 1}+\left(1-s^{L}\right) N D_{t}^{R, 1}+s^{L} I D_{t}^{L, 1}+\left(1-s^{L}\right) I D_{t}^{R, 1}
$$

(14) Resource constraint (Sector 2: Non-affected Sector)

$$
Y_{t}^{2}=I_{t}^{2}+I_{t}^{1}+G_{t}+s^{L} N D_{t}^{L, 2}+\left(1-s^{L}\right) N D_{t}^{R, 2}+s^{L} I D_{t}^{L, 2}+\left(1-s^{L}\right) I D_{t}^{R, 2}
$$

\section{D.2 Ricardian households}

(15) Marginal utility (Ricardian Households)

$$
U^{\prime}\left(C_{t}^{R}\right)=\frac{1}{\left(C_{t}^{R}\right)^{\sigma}}
$$

(16) Intertemporal Euler (Ricardian households)

$$
\frac{U^{\prime}\left(C_{t}^{R}\right)}{U^{\prime}\left(E_{t} C_{t+1}^{R}\right)}=\frac{\beta\left(1+r_{t}\right)}{1+E_{t} \pi_{t+1}^{C, R}}
$$

(17) Consumer price deflator (Ricardian households)

$$
P_{t}^{C, R}=\left(\psi^{N, R}\left(P_{t}^{N}\right)^{1-\sigma^{N D}}+\psi^{D, R}\left(P_{t}^{D, R}\right)^{1-\sigma^{N D}}\right)^{\frac{1}{1-\sigma^{N D}}}
$$

(18) Consumer price inflation (Ricardian households)

$$
\pi_{t}^{C, R}=\frac{P_{t}^{C, R}}{P_{t-1}^{C, R}}-1
$$

(19) Non-durable goods consumption (Ricardian Households)

$$
N D_{t}^{R}=C_{t}^{R} \bar{\psi}^{N, R}\left(\frac{P_{t}^{C, R}}{P_{t}^{N}}\right)^{\sigma^{N D}}
$$


(20) Durable goods price deflator (Ricardian households)

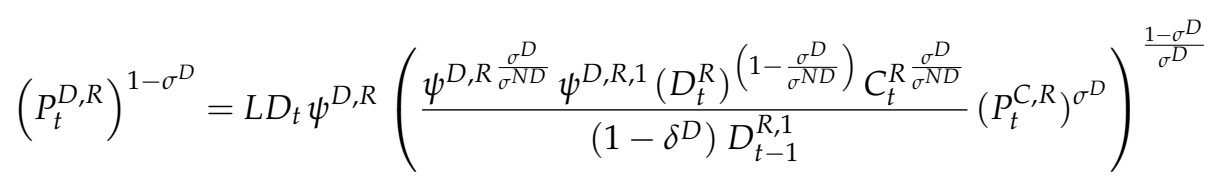

$$
\begin{aligned}
& +\left(1-L D_{t}\right) \psi^{D, R, 1}\left(P_{t}^{D, 1}\left(1+\tau_{t}^{V A T}\right)\left(1+\gamma^{D}\left(\frac{I D_{t}^{R, 1}}{D_{t}^{R, 1}}-\delta^{D}\right)\right) R_{t}^{D, R, 1}\right)^{1-\sigma^{D}} \\
& +\left(1-L D_{t}\right) \psi^{D, R, 2}\left(P_{t}^{D, 2}\left(1+\tau_{t}^{V A T}\right)\left(1+\gamma^{D}\left(\frac{I D_{t}^{R, 2}}{D_{t}^{R, 2}}-\delta^{D}\right)\right) R_{t}^{D, R, 2}\right)^{1-\sigma^{D}}
\end{aligned}
$$

with $P_{t}^{D, 1}=P_{t}^{Y, 1}, P_{t}^{D, 2}=P_{t}^{r e t}$ and

$R_{t}^{D, R, j}=\delta^{D}+r_{t}-\left(E_{t} \pi_{t+1}^{D, j}-E_{t} \pi_{t+1}^{Y, j}\right)-\gamma^{D}\left(\frac{E_{t} I D_{t+1}^{R, j}}{D_{t}^{R, j}}-\delta^{D}\right)+\gamma^{D}\left(\frac{I D_{t}^{R, j}}{D_{t-1}^{R, j}}-\delta^{D}\right)-E_{t} \Delta \tau_{t+1}^{V A T}$.

(21) Durable goods composition (Ricardian households)

$$
D_{t}^{R}=\left(\psi^{D, R, 1 \frac{1}{\sigma^{D}}} D_{t}^{R, 1 \frac{\sigma^{D}-1}{\sigma^{D}}}+\psi^{D, R, 2 \frac{1}{\sigma^{D}}} D_{t}^{R, 2 \frac{\sigma^{D}-1}{\sigma^{D}}}\right)^{\frac{\sigma^{D}}{\sigma^{D}-1}}
$$

(22) Sectoral durable goods consumption (Ricardian households)

$$
\begin{aligned}
D_{t}^{R, j}=D_{t-1}^{R, j}\left(1-\delta^{D}\right) L D_{t}+\psi^{D, R} \frac{\sigma^{D}}{\sigma^{N D}}\left(D_{t}^{R}\right)^{1-\frac{\sigma^{D}}{\sigma^{N D}} \times} \\
\psi^{D, R, j}\left(1-L D_{t}\right)\left(\frac{P_{t}^{C, R}}{P_{t}^{D, j}\left(1+\tau_{t}^{V A T}\right)\left(1+\gamma^{D}\left(\frac{I D_{t}^{R, j}}{D_{t}^{R, j}}-\delta^{D}\right)\right) R_{t}^{D, j}}\right)^{\sigma^{D}} C_{t}^{R} \frac{\sigma^{D}}{\sigma^{D D}}
\end{aligned}
$$

(23) Sectoral durable consumption stock (Ricardian households)

$$
D_{t}^{R, j}=I D_{t}^{R, j}+\left(1-\delta^{D}\right) D_{t-1}^{R, j}
$$

(24) Total durable goods consumption flows (Ricardian Households)

$$
I D_{t}^{R}=I D_{t}^{R, 1}+I D_{t}^{R, 2}
$$

(25) Total durable goods stock (Ricardian Households)

$$
D_{t}^{R}=D_{t}^{R, 1}+D_{t}^{R, 2}
$$

(26) Sectoral non-durable goods consumption (Ricardian Household)

$$
N D_{t}^{R, j}=N D_{t}^{R}\left(1-\left(L D_{t}\right)\right) \psi^{N, j}\left(\frac{P_{t}^{N}}{P_{t}^{N, j}\left(1+\tau_{t}^{V A T}\right)\left(1+L D_{t}\right)}\right)^{\sigma^{N D}}
$$

with $P_{t}^{N, 1}=P_{t}^{Y, 1}, P_{t}^{N, 2}=P_{t}^{r e t}$.

(27) Total non-durable goods consumption (Ricardian households)

$$
N D_{t}^{R}=N D_{t}^{R, 1}+N D_{t}^{R, 2}
$$




\section{D.3 Liquidity-constrained household}

(28) Marginal utility (LC household)

$$
U^{\prime}\left(C_{t}^{L}\right)=\frac{1}{C_{t}^{L}}
$$

(29) Budget constraint (LC household)

$$
F S_{t}+\left(1+\tau_{t}^{V A T}\right)\left(P_{t}^{N, 1} N D_{t}^{L, 1}+P_{t}^{N, 2} N D_{t}^{L, 2}+P_{t}^{D, 1} I D_{t}^{L, 1}+P_{t}^{D, 2} I D_{t}^{L, 2}\right)=L_{t}^{2} W_{t}^{2}+L_{t}^{1} W_{t}^{1}+Z_{t}^{L}
$$

(30) Consumer price deflator (LC household)

$$
P_{t}^{C, L}=\left(\psi^{N, L}\left(P_{t}^{N}\right)^{1-\sigma^{N D}}+\psi^{D, L}\left(P_{t}^{D, L}\right)^{1-\sigma^{N D}}\right)^{\frac{1}{1-\sigma^{N D}}}
$$

(31) Consumer price inflation (LC household)

$$
\pi_{t}^{C, L}=\frac{P_{t}^{C, L}}{P_{t-1}^{C, L}}-1
$$

(32) Durable goods consumption (LC household)

$$
N D_{t}^{L}=C_{t}^{L} \psi^{N, L}\left(\frac{P_{t}^{C, L}}{P_{t}^{N}}\right)^{\sigma^{N D}}
$$

(33) Durable price deflator (LC household)

$$
\begin{aligned}
\left(P_{t}^{D, L}\right)^{1-\sigma^{D}}= & L D_{t} \psi^{D, L, 1}\left(\frac{\psi^{D, L, 1} \psi^{D, \frac{\sigma^{D}}{\sigma^{N D}}}\left(D_{t}^{L}\right)^{1-\frac{\sigma^{D}}{\sigma^{N D}}}\left(C_{t}^{L} \frac{\sigma^{D}}{\sigma^{N D}}\right.}{\left(1-\delta^{D}\right) D_{t-1}^{L, 1}}\left(P_{t}^{C, L}\right)^{\sigma^{D}}\right)^{\frac{1-\sigma^{D}}{\sigma^{D}}} \\
& +\left(1-L D_{t}\right) \psi^{D, L, 1}\left(P_{t}^{D, 1}\left(1+\tau_{t}^{V A T}\right)\left(1+\gamma^{D}\left(\frac{I D_{t}^{L, 1}}{D_{t}^{L, 1}}-\delta^{D}\right)\right) R_{t}^{D, L, j}\right)^{1-\sigma^{D}} \\
& +\left(1-L D_{t}\right) \psi^{D, L, 2}\left(P_{t}^{D, 2}\left(1+\tau_{t}^{V A T}\right)\left(1+\gamma^{D}\left(\frac{I D_{t}^{L, 2}}{D_{t}^{L, 2}}-\delta^{D}\right)\right) R_{t}^{D, L, j}\right)^{1-\sigma^{D}}
\end{aligned}
$$

with $P_{t}^{D, 1}=P_{t}^{Y, 1}, P_{t}^{D, 2}=P_{t}^{r e t}$ and $R_{t}^{D, L, j}=\delta^{D}+E_{t} \pi_{t+1}^{C, L}+E_{t} g_{t+1}^{C, L}+\frac{1}{\beta}-1-E_{t} \pi_{t+1}^{N, j}-E_{t} \pi_{t+1}^{Y, j}-\gamma^{D}\left(\frac{E_{t} I D_{t+1}^{L, j}}{D_{t}^{L, j}}-\delta^{D}\right)+\gamma^{D}\left(\frac{I D_{t}^{L, j}}{D_{t-1}^{L, j}}-\delta^{D}\right)-E_{t} \Delta \tau_{t+1}^{V A T}$.

(34) Durable goods composition (LC household)

$$
D_{t}^{L}=\left(\psi^{D, L, 1} \frac{1}{\sigma^{D}}\left(D_{t}^{L, 1}\right)^{\frac{\sigma^{D}-1}{\sigma^{D}}}+\psi^{D, L, 2 \frac{1}{\sigma^{D}}}\left(D_{t}^{L, 2}\right)^{\frac{\sigma^{D}-1}{\sigma^{D}}}\right)^{\frac{\sigma^{D}}{\sigma^{D}-1}}
$$


(35) Sectoral durable goods consumption (LC household)

$$
\begin{aligned}
D_{t}^{L, j}=L D_{t}\left(1-\delta^{D}\right) D^{L, j}{ }_{t-1}+\psi^{D, L} \frac{\sigma^{D}}{\sigma^{N D}}\left(D_{t}^{L}\right)^{1-\frac{\sigma^{D}}{\sigma^{N D}}} \times \\
\psi^{D, L, j}\left(1-L D_{t}\right)\left(\frac{P_{t}^{C, L}}{P_{t}^{D, j}\left(1+\tau_{t}^{V A T, D}\right)\left(1+\gamma^{D}\left(\frac{I D_{t}^{L, j}}{D_{t}^{L, j}}-\delta^{D}\right)\right) R_{t}^{D, L, j}}\right)^{\sigma^{D}}\left(C_{t}^{L}\right)^{\frac{\sigma^{D}}{\sigma^{N D}}}
\end{aligned}
$$

(36) Consumption growth equivalent (LC household)

$$
g_{t}^{C, L}=\frac{C_{t}^{L}}{C_{t-1}^{L}}-1
$$

(37) Sector 1 non-negativity constraint durable goods consumption (LC household)

$$
I D_{t}^{L, 1}=\max \left[0, D_{t}^{L, 1}-\left(1-\delta^{D}\right) D_{t-1}^{L, 1}\right]
$$

(38) Sector 2 durable goods stock (LC household)

$$
D_{t}^{L, 2}=I D_{t}^{L, 2}+\left(1-\delta^{D}\right) D_{t-1}^{L, 2}
$$

(39) Total durable goods consumption flows (LC household)

$$
I D_{t}^{L}=I D_{t}^{L, 1}+I D_{t}^{L, 2}
$$

(40) Total durable goods stock (LC household)

$$
D_{t}^{L}=D_{t}^{L, 1}+D_{t}^{L, 2}
$$

(41) Sectoral non-durable goods consumption (LC household)

$$
N D_{t}^{L, j}=\left(1-L D_{t}\right) \psi^{N, j}\left(\frac{P_{t}^{N}}{P_{t}^{N, j}\left(1+\tau_{t}^{V A T}\right)}\right)^{\sigma^{N D}} N D_{t}^{L}
$$

with $P_{t}^{N, 1}=P_{t}^{Y, 1}, P_{t}^{N, 2}=P_{t}^{r e t}$.

(42) Total non-durable goods consumption (LC household)

$$
N D_{t}^{L}=N D_{t}^{L, 1}+N D_{t}^{L, 2}
$$

(43) Implicit discount factor (LC household)

$$
r_{t}^{L}=E_{t} g_{t+1}^{C, L}+E_{t} \pi_{t+1}^{C, L}
$$

\section{D.4 Fiscal and Monetary Policy}

(44) Government bonds yield

$$
1+r_{t}^{B}=\left(1+r_{t}\right)\left(1-\frac{u_{t}^{B}}{U^{\prime}\left(C_{t}^{R}\right)}\right)
$$


(45) Government budget

$$
\begin{aligned}
B_{t}=G_{t}+Z_{t}^{R}+Z_{t}^{L}+\left(1-\frac{u^{B} t}{U^{\prime}\left(C_{t}^{R}\right)}\right)\left(1+r_{t-1}\right) B_{t-1}-L_{t}^{2} W_{t}^{2} \bar{\tau}^{W}-L_{t}^{1} \bar{\tau}^{W} W_{t}^{1}-T_{t} & \\
& -N D_{t} P_{t}^{r e t} \tau_{t}^{V A T}-I D_{t} P_{t}^{r e t} \tau_{t}^{V A T}
\end{aligned}
$$

(46) Lump sum tax/transfer rule

$$
T_{t}=\phi_{T} T_{t-1}+\left(1-\phi_{T}\right)\left(\phi_{b y}\left(\frac{B_{t}}{y_{t}}-\frac{\bar{B}}{\bar{y}}\right)+\phi_{b}\left(B_{t}-B_{t-1}\right)\right),
$$

(47) VAT rate change (in PP)

$$
\Delta \tau_{t}^{V A T}=\tau_{t}^{V A T}-\tau_{t-1}^{V A T}
$$

(48) Debt-to-GDP ratio

$$
b_{t}=\frac{B_{t}}{4\left(Y_{t}^{2}+Y_{t}^{1}\right)}
$$

(49) Value added tax revenue

$$
T_{t}^{V A T, R E V}=N D_{t} \tau_{t}^{V A T}+I D_{t} \tau_{t}^{V A T}
$$

(50) Monetary policy rate

$$
i_{t}=\left(\frac{1-\beta}{\beta}\right) e_{t}^{Z L B}+\left(1-e_{t}^{Z L B}\right)\left(\max \left[i_{,}\left(1-\phi^{i}\right)\left(\bar{r}+\phi^{\pi} \pi_{t}^{C}+\phi^{d y}\left(Y_{t}-Y_{t-1}\right)+\phi^{y} \frac{Y_{t}}{\bar{Y}}\right)+\phi^{i} i_{t-1}+e_{t}^{i}\right]\right)
$$

(51) Nominal interest rate

$$
i_{t}=r_{t}+E_{t} \pi_{t+1}^{Y}
$$

\section{D.5 Aggregation}

(52) Aggregate GDP

$$
Y_{t}=Y_{t}^{1}+Y_{t}^{2}
$$

(53) Aggregate labor volume

$$
L_{t}=L_{t}^{1}+L_{t}^{2}
$$

(54) Aggregate investment

$$
I_{t}=I_{t}^{1}+I_{t}^{2}
$$

(55) Aggregate non-durable goods consumption

$$
N D_{t}=s^{L}\left(N D_{t}^{L, 1}+N D_{t}^{L, 2}\right)+\left(1-s^{L}\right)\left(N D_{t}^{R, 1}+N D_{t}^{R, 2}\right)
$$

(56) Aggregate durable goods consumption

$$
I D_{t}=s^{L}\left(I D_{t}^{L, 1}+I D_{t}^{L, 2}\right)+\left(1-s^{L}\right)\left(I D_{t}^{R, 1}+I D_{t}^{R, 2}\right)
$$

(57) Aggregate durable goods stock

$$
D_{t}=s^{L} D_{t}^{L}+\left(1-s^{L}\right) D_{t}^{R}
$$

(58) Aggregate consumption

$$
C_{t}=N D_{t}+I D_{t}
$$


(59) Consumption deflator

$$
P_{t}^{C}=P_{t}^{r e t}\left(1+\tau_{t}^{V A T}\right)
$$

(60) Consumer price inflation

$$
\pi_{t}^{C}=\left(1-L D_{t}\right)\left({ }_{s}{ }^{C P I, 1}\left(\pi_{t}^{Y, 1}+\frac{\Delta \tau_{t}^{V A T}}{1+\tau_{t}^{V A T}}\right)+s^{C P I, 2}\left(\pi_{t}^{r e t}+\frac{\Delta \tau_{t}^{V A T}}{1+\tau_{t}^{V A T}}\right)\right)+L D_{t}\left(\pi_{t}^{r e t}+\frac{\Delta \tau_{t}^{V A T}}{1+\tau_{t}^{V A T}}\right)
$$

(61) Producer price inflation

$$
\pi_{t}^{Y}=\left(1-L D_{t}\right)\left(\pi_{t}^{Y, 1} s_{t}^{1}+\pi_{t}^{Y, 2} s_{t}^{2}\right)+\pi_{t}^{Y, 2} L D_{t}
$$

(62) Savings rate

$$
S Q_{t}=\frac{Z_{t}+Y_{t}-G_{t}-C_{t}-L_{t}^{2} W_{t}^{2} \bar{\tau}^{W}-L_{t}^{1} \bar{\tau}^{W} W_{t}^{1}-T_{t}}{Z_{t}+Y_{t}-G_{t}-L_{t}^{2} W_{t}^{2} \bar{\tau}^{W}-L_{t}^{1} \bar{\tau}^{W} W_{t}^{1}-T_{t}}
$$




\section{References}

Atalay, E. (2017). How Important Are Sectoral Shocks? American Economic Journal: Macroeconomics 9(4), 254-280.

Bachmann, R., B. Born, O. Goldfayn-Frank, G. Kocharkov, R. Luetticke, and M. Weber (2021). A Temporary VAT Cut as Unconventional Fiscal Policy. NBER Working Paper 29442, National Bureau of Economic Research.

Baqaee, D. and E. Farhi (2020). Nonlinear Production Networks with an Application to the Covid-19 Crisis. NBER Working Papers 27281, National Bureau of Economic Research, Inc.

Barrell, R. and M. Weale (2009). The Economics of a Reduction in VAT. Fiscal Studies 30(1), 17-30.

Barsky, R., C. Boehm, C. House, and M. Kimball (2019). Monetary Policy and Durable Goods. 2019 Meeting Papers 264, Society for Economic Dynamics.

Beck, G., A. Dijs, X. Jaravel, S. Kessing, and S. Siegloch (2021). Analyse der Verbraucherpreisentwicklung nach Senkung der Mehrwertsteuer. Bundesministerium für Justiz und Verbraucherschutz (BMJV), Berlin.

Burgert, M., W. Roeger, J. Varga, J. in 't Veld, and L. Vogel (2020). A Global Economy Version of QUEST: Simulation Properties. European Economy - Discussion Papers 2015 - 126, Directorate General Economic and Financial Affairs (DG ECFIN), European Commission.

Calvo, G. A. (1983). Staggered Prices in a Utility-Maximizing Framework. Journal of Monetary Economics 12(3), 383-398.

Casalis, A. and G. Krustev (2020). Consumption of Durable Goods in the Euro Area. ECB Economic Bulletin Articles 5.

Christiano, L. J., M. S. Eichenbaum, and M. Trabandt (2015). Understanding the Great Recession. American Economic Journal: Macroeconomics 7(1), 110-167.

Claus, I. (2013). Is the Value Added Tax a useful Macroeconomic Stabilization Instrument? Economic Modelling 30(C), 366-374.

Clemens, M. and W. Roeger (2022). Durable Consumption, Limited VAT Pass-Through and Stabilization Effects of Temporary VAT Changes. DIW Discussion Paper 2004.

Coenen, G., R. Straub, and M. Trabandt (2013). Gauging the Effects of Fiscal Stimulus Packages in the Euro Area. Journal of Economic Dynamics and Control 37(2), 367-386.

Correia, I., E. Farhi, J. P. Nicolini, and P. Teles (2013). Unconventional Fiscal Policy at the Zero Bound. American Economic Review 103(4), 1172-1211.

Crossley, T., H. Low, and C. Sleeman (2014). Using a Temporary Indirect Tax Cut as a Fiscal Stimulus: Evidence from the UK. IFS Working Papers W14/16, Institute for Fiscal Studies.

Crossley, T. F., H. Low, and M. Wakefield (2009). The Economics of a Temporary VAT Cut. Fiscal Studies 30(1), 3-16.

Fuest, C., F. Neumeier, and A. Peichl (2021). Hat die Mehrwertsteuersenkung den Konsum belebt? ifo Schnelldienst Digital 2(1).

Fuest, C., F. Neumeier, and D. Stöhlker (2020). The Pass-Through of Temporary VAT Rate Cuts in German Supermarket Retail. ifo Working Paper 341.

Grabka, M. M. and C. Halbmeier (2019). Vermögensungleichheit in Deutschland bleibt trotz deutlich steigender Nettovermögen anhaltend hoch. DIW Wochenbericht 86(40), 735-745. 
Guerrieri, V., G. Lorenzoni, L. Straub, and I. Werning (2020). Macroeconomic Implications of COVID-19: Can Negative Supply Shocks Cause Demand Shortages? NBER Working Papers 26918, National Bureau of Economic Research, Inc.

Harmenberg, K. and E. Öberg (2021). Consumption dynamics under time-varying unemployment risk. Journal of Monetary Economics 118(C), 350-365.

Hinterlang, N., S. Moyen, O. Röhe, and N. Stähler (2020). Gauging the Effects of the German COVID-19 Fiscal Stimulus Package.

McKay, A. and J. F. Wieland (2021). Lumpy Durable Consumption Demand and the Limited Ammunition of Monetary Policy. Staff Report 622, Federal Reserve Bank of Minneapolis.

Monacelli, T. (2009). New Keynesian Models, Durable Goods, and Collateral Constraints. Journal of Monetary Economics 56(2), 242-254.

Montag, F., A. Sagimuldina, and M. Schnitzer (2020). Are Temporary Value-Added Tax Reductions Passed on to Consumers? Evidence from Germany's Stimulus. CEPR Discussion Papers 15189, C.E.P.R. Discussion Papers.

Ogaki, M. and C. M. Reinhart (1998). Measuring Intertemporal Substitution: The Role of Durable Goods. Journal of Political Economy 106(5), 1078-1098.

Pakoš, M. (2011). Estimating Intertemporal and Intratemporal Substitutions When Both Income and Substitution Effects Are Present: The Role of Durable Goods. Journal of Business Economic Statistics 29(3), 439-454.

Rotemberg, J. J. and M. Woodford (1996). Imperfect Competition and the Effects of Energy Price Increases on Economic Activity. Journal of Money, Credit and Banking 28(4), 550-577.

Sims, E. and J. Wolff (2018). The State-Dependent Effects of Tax Shocks. European Economic Review 107(C), 57-85. 